Review

\title{
Nanostructured Gas Sensors: From Air Quality and Environmental Monitoring to Healthcare and Medical Applications
}

\author{
Xiaohu Chen ${ }^{1}$ D , Michelle Leishman ${ }^{2}$, Darren Bagnall ${ }^{3}$ and Noushin Nasiri ${ }^{1, *(D)}$ \\ 1 NanoTech Laboratory, School of Engineering, Faculty of Science and Engineering, Macquarie University, \\ Sydney, NSW 2109, Australia; jayden.chen@hdr.mq.edu.au \\ 2 Department of Biological Sciences, Macquarie University, Sydney, NSW 2109, Australia; \\ michelle.leishman@mq.edu.au \\ 3 School of Engineering, Faculty of Science and Engineering, Macquarie University, \\ Sydney, NSW 2109, Australia; darren.bagnall@mq.edu.au \\ * Correspondence: noushin.nasiri@mq.edu.au
}

Citation: Chen, X.; Leishman, M.; Bagnall, D.; Nasiri, N.

Nanostructured Gas Sensors: From Air Quality and Environmental Monitoring to Healthcare and Medical Applications. Nanomaterials 2021, 11, 1927. https://doi.org/ 10.3390/nano11081927

Academic Editor: Sergei Kulinich

Received: 15 June 2021

Accepted: 21 July 2021

Published: 26 July 2021

Publisher's Note: MDPI stays neutral with regard to jurisdictional claims in published maps and institutional affiliations.

\begin{abstract}
In the last decades, nanomaterials have emerged as multifunctional building blocks for the development of next generation sensing technologies for a wide range of industrial sectors including the food industry, environment monitoring, public security, and agricultural production. The use of advanced nanosensing technologies, particularly nanostructured metal-oxide gas sensors, is a promising technique for monitoring low concentrations of gases in complex gas mixtures. However, their poor conductivity and lack of selectivity at room temperature are key barriers to their practical implementation in real world applications. Here, we provide a review of the fundamental mechanisms that have been successfully implemented for reducing the operating temperature of nanostructured materials for low and room temperature gas sensing. The latest advances in the design of efficient architecture for the fabrication of highly performing nanostructured gas sensing technologies for environmental and health monitoring is reviewed in detail. This review is concluded by summarizing achievements and standing challenges with the aim to provide directions for future research in the design and development of low and room temperature nanostructured gas sensing technologies.
\end{abstract}

Keywords: air quality; environmental monitoring; breath analysis; nanostructured gas sensors

\section{Introduction}

From smog hanging over cities to smoke inside the home, air pollution poses a major threat to both climate and health. Poisonous gases, such as $\mathrm{NO}_{2}, \mathrm{SO}_{2}$, and $\mathrm{CO}_{2}$ etc. acidic gases and basic gas of $\mathrm{NH}_{3}$, in the environment are posing increasingly risks to the ecosystem and public health due to the intensification of human activity. For instance, emitted $\mathrm{SO}_{2}$ gas oxidation to $\mathrm{SO}_{3}$ followed by reaction with water droplets (moisture) leads to the formation of acid rain $\left(\mathrm{H}_{2} \mathrm{SO}_{4}\right)$, which causes skin irritation and ulcers, decreases soil fertility, corrodes metallic objects and increases the acidity of water bodies [1,2]. In addition, $\mathrm{CO}_{2}$ and $\mathrm{NO}_{2}$ gas molecules can readily dissolve in the water droplets in clouds, causing the formation of $\mathrm{H}_{2} \mathrm{CO}_{3}$ and $\mathrm{HNO}_{3}$, respectively, affecting natural balance of rivers, lakes and soils and damaging wildlife and vegetation $[2,3]$.

Among gases that cause the most air pollution, volatile organic compounds (VOCs) emissions are amongst the biggest environmental problems today [4]. When exposed to sunlight, VOCs react with other gases to form ground-level smog compounds, which stimulate diseases in plants, inhibit seed production and hinder fertilization [5]. Prolonged exposure to VOCs can cause severe health issues in humans including chronic obstructive pulmonary disease, lung cancer and strokes [6]. According to the World Health Organization (WHO), the combined effects of indoor and outdoor air pollution cause about 
7 million premature deaths every year [7], and it is estimated that this number will double by 2050 [8].

In addition to air pollution, several VOCs present in the human breath are related to important metabolic processes and if detected can serve as an effective non-invasive tool for health monitoring [9]. The concentration of endogenous compounds, including inorganic gases (e.g., nitric oxide, carbon monoxide) and VOCs (e.g., ethane, pentane, ammonia, acetone and ethanol), can be altered in the breath of patients with specific pathologies and, thus, can be utilized as breath markers for diseases [10,11]. While conventional gas sensing techniques such as gas chromatography-mass spectrometry (GC-MS) are gold standard, they are expensive and time-consuming, greatly limiting the potential for real-time measurement. In the past decade, efforts have been shifting from traditional chemical and imaging diagnostic methods to the biotechnology and commercial electronic industries for early-stage and point-of-care diagnostics [12]. A paradigm shift may be offered by the convergence of novel nanoelectronic technologies and big data analytical methodologies [13], providing novel opportunities to improve the quality of healthcare while decreasing costs by the very early-stage detection and prevention of fatal and chronic diseases $[9,10,12,13]$.

The use of advanced nanostructured sensing materials is one of the promising detection techniques for monitoring low concentrations of VOCs in a complex gas mixture, for air quality, environmental monitoring [14], health, and medical applications [15]. Among many nanostructured gas sensing technologies, metal oxide semiconductors represent a class of unique materials due to their low cost, high sensitivity, simple fabrication and excellent reproducibility [9]. However, high operating temperature and consequently, excessive power consumption and poor long-term stability, are significant operational challenges [9], hindering their real-world application as miniaturized portable gas sensors [10]. There are continuing efforts toward the development of efficient sensing technologies for room temperature operation devices either by tailoring the property of the sensing layer with desired morphologies or designing novel nanostructures exploiting distinct properties of some nanomaterials.

Here, we present some of the key innovations in nanostructured sensors that are leading the way in sensitive and selective gas sensing at low operating temperatures. We focus on the impact of the nanoscale material hierarchy, discussing the similarities and differences across nanomaterials, the nanostructured morphologies as well as sensing mechanisms for low temperature detection of VOC gases in different sensing environments. We conclude with a review of issues that need to be overcome to enable the engineering of the next generation of miniaturized low-temperature nanostructured gas sensors for air quality, environmental monitoring, health, and medical applications.

\section{Air Quality and Environmental Monitoring}

With the increasing trend towards urbanization, concern for high levels of pollution and greenhouse emissions due to higher demands on transport, and energy consumption is increasing day by day [16]. Air pollutants and greenhouse gases, especially high levels of nitrogen dioxide $\left(\mathrm{NO}_{2}\right)$, sulphur dioxide $\left(\mathrm{SO}_{2}\right)$ and carbon dioxide $\left(\mathrm{CO}_{2}\right)$ are considered as the most significant environmental risks to public health in urban areas as well as climate change around the globe [17].

\subsection{Nitrogen Dioxide $\left(\mathrm{NO}_{2}\right)$}

$\mathrm{NO}_{2}$ is a highly poisonous toxic gas produced as a byproduct of internal combustion engines in vehicles, and the household or commercial combustion of coal, gas, oil, or wood $[18,19]$. It is one of the most common air pollutants (particulate matter, ozone, $\mathrm{NO}_{2}$ and $\mathrm{SO}_{2}$ ) that is used as an air quality indicator globally by the World Health Organization (WHO) [20]. $\mathrm{NO}_{2}$ is considered dangerous for human health at concentrations greater than 4 parts per million (ppm) at which it can anesthetize our sense of smell [1], and from there overexposure results in respiratory and cardiovascular illnesses and diseases [19]. 
$\mathrm{NO}_{2}$ can cause severe environmental problems such as smog [21], acid rain [22,23], and nutrient pollution in coastal waters [24]. According to the U.S. Occupational Safety and Health Administration (OSHA), the permissible exposure limit for toxic industrial $\mathrm{NO}_{2}$ gas is $5 \mathrm{ppm}$ [25]. Therefore, the development of sensitive and selective $\mathrm{NO}_{2}$ gas sensors with low ppm detection and operating without heating requirements is critical for many practical applications, including continuous monitoring of air quality and health.

Among a wide range of sensing materials, metal oxide semiconductors have attracted significant attention due to their low cost, easy fabrication, simplicity of use, large number of detectable gases, compact size and simple sensing operation $[9,15]$. However, their high operating temperature (to accelerate the sensing kinetics) and consequently high-power consumption, hinder their real-world application as portable and/or wearable devices [10]. In addition, they suffer from long-term stability as their high operating temperature induces nanostructure grain growth that can result in the significant reduction of sensing performance [9]. The urgent task, therefore, is to reduce the operating temperature of metal oxide-based gas sensors.

For this purpose, Geng et al. [26] reported the utilization of white-light illumination, as an external activation energy source, to accelerate the sensing response (also termed as gas sensitivity, defined as $S=\frac{\left|R_{g}-R_{a}\right|}{R_{a}}$, where $R_{g}$ and $R_{a}$ are the electrical resistance upon exposure to targeted gas and air, respectively) at room temperature. Using a onestep hydrothermal synthesis technique, they developed a $\mathrm{p}-\mathrm{n}$ heterojunction of reduced graphene oxide (rGO) and $\mathrm{ZnO}_{1-x}$ nanocomposite made of enwrapped $\mathrm{ZnO}$ nanosheets (Figure 1a) and gauze-like thin layers of rGO (Figure 1c, inset) for ppb-level detection of $\mathrm{NO}_{2}$ gas molecules at room temperature. Upon white light illumination, the sensing material exhibited an enhanced response and recovery kinetics compared to the dark condition. This is attributed to the significant change in the light absorption spectra of the $\mathrm{rGO} / \mathrm{ZnO}_{1-\mathrm{x}}$ nanocomposite which was red-shifted and extended to the entire visible light region. In the case of pure $\mathrm{ZnO}$ film, white light illumination is not efficient as photons with excitation energies greater than $3.3 \mathrm{eV}$ are required to accelerate the sensing response [27,28]. In contrast, the $\mathrm{rGO} / \mathrm{ZnO}_{1-\mathrm{x}}$ nanocomposite can absorb low-energy visible-light photons, resulting in significantly higher sensing response of 4.66 under white-light illumination compared to 0.31 of the pure $\mathrm{ZnO}$ nanofilm at the same conditions [26]. In addition, the fabricated nanocomposite demonstrated a faster response dynamic upon exposure to $\mathrm{NO}_{2}$ gas molecules with 1.5- and 2.5-min response and recovery time respectively, compared to that over 10- and 20-min, for the pure $\mathrm{ZnO}$ nanofilm. The synergistic effects between $\mathrm{ZnO}$ nanosheets, as gas reaction units and the rGO nanolayers, as the photosensitizer provide a strong electron-donor and electron-transfer pathway, and enhances the sensing performance of the nanocomposite compared to the pure $\mathrm{ZnO}$ sensor [26].

Figure $1 \mathrm{~b}$ presents the sensing performance of the fabricated nanocomposite with different $\mathrm{rGO} / \mathrm{ZnO}_{1-\mathrm{x}}$ weight ratio for $\mathrm{NO}_{2}$ gas molecules with $100 \mathrm{ppb}$ concentration at room temperature $\left(25^{\circ} \mathrm{C}\right)$. The gas sensing response increased from $0.7 \mathrm{of} \mathrm{rGO} / \mathrm{ZnO}_{1-\mathrm{x}}$ film with $0.2 \mathrm{wt} \%$ ratio to 4.66 for the film with $2.0 \mathrm{wt} \%$ ratio. This is attributed to the participation of more electrons created during adsorption as electrons are transferred from rGO to $\mathrm{ZnO}$ [26]. In addition, the large surface density of adsorption sites in the $\mathrm{rGO} / \mathrm{ZnO}_{1-\mathrm{x}}$ nanocomposite resulted in more physiosorbed $\mathrm{NO}_{2}$ on the surface. However, further increase in the weight ratio of $\mathrm{rGO} / \mathrm{ZnO}_{1-\mathrm{x}}$ to $10 \%$ reduced the sensing performance of the hybrid device to less than 1 . This reduction in sensing performance is attributed to the $\mathrm{ZnO}$ nanosheets covered by rGO layers, resulting in a significant reduction in gas molecules adsorption on $\mathrm{ZnO}$ surface [26]. Increasing the $\mathrm{NO}_{2}$ gas concentration from 50 to $400 \mathrm{ppb}$ resulted in a linear enhancement in sensor's response from 2.5 to 19 . The fabricated nanocomposites demonstrated a linear enhancement in sensing performance upon exposure to $\mathrm{NO}_{2}$ gas with concentration increasing from 50 to $400 \mathrm{ppb}$. Furthermore, the sensing response was investigated upon exposure to a variety of targeted gases with different concentrations (Figure 1c), demonstrating a remarkable selectivity towards $\mathrm{NO}_{2}$ $(\mathrm{S}=4.6)$ with a neglectable response to other gases including $\mathrm{SO}_{2}(\mathrm{~S}<0.6,100 \mathrm{ppm}), \mathrm{H}_{2}$ 
( $\mathrm{S}<0.5,400 \mathrm{ppm}), \mathrm{HCHO}(\mathrm{S}<0.4,10 \mathrm{ppm}), \mathrm{CO}(\mathrm{S}<0.3,100 \mathrm{ppm})$ and $\mathrm{NH}_{3}(\mathrm{~S}<0.2$, $100 \mathrm{ppm}$ ) [26]. This higher sensitivity towards $\mathrm{NO}_{2}$ could be attributed to the higher electron transfer between $\mathrm{NO}_{2}$ and the surface of fabricated nanocomposites at room temperature compared to other targeted gases. In fact, a higher operating temperature might be required to enhance the sensitivity of the fabricated sensor towards other gases [29].
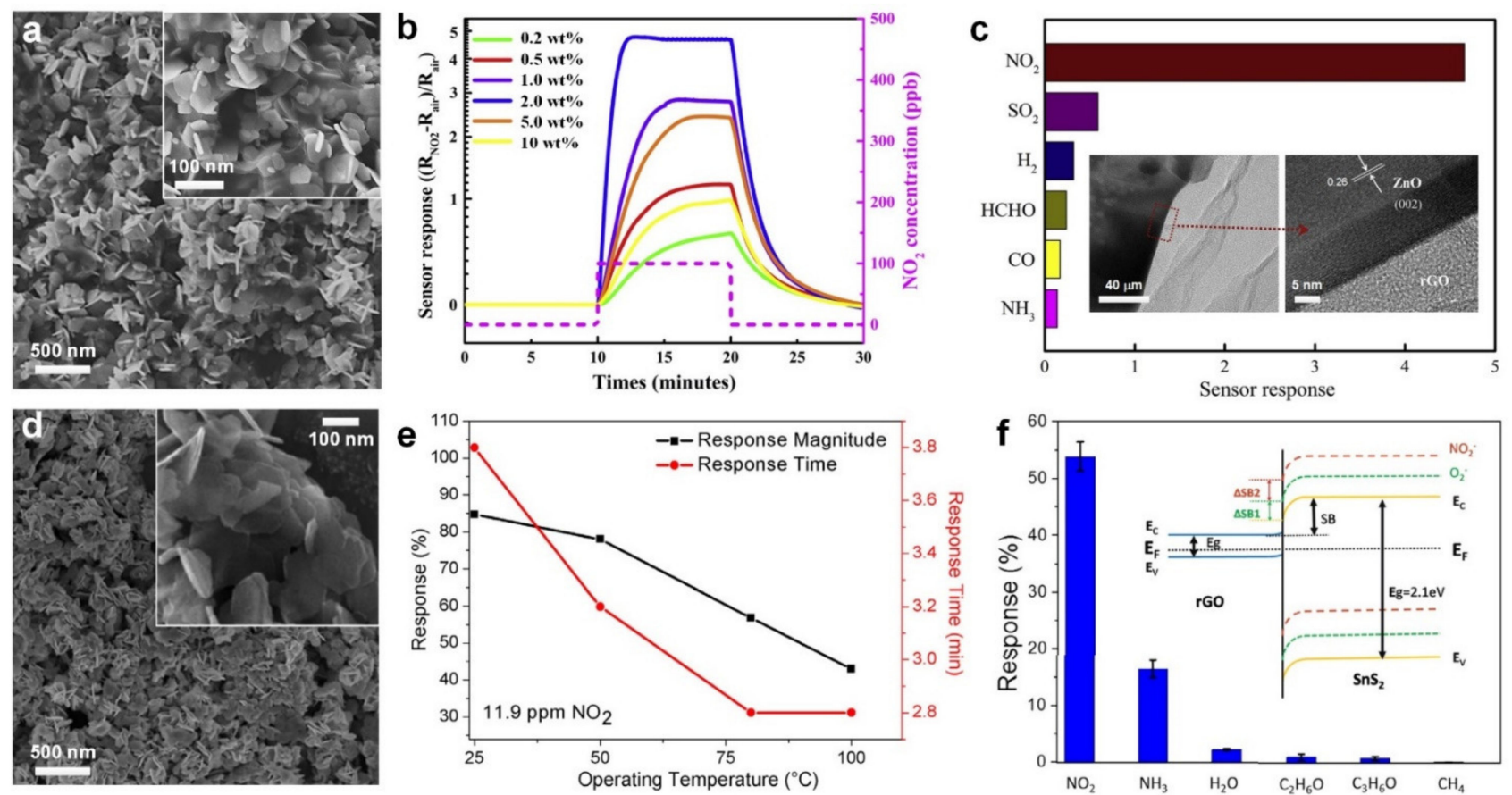

Figure 1. (a) FE-SEM images and (b) the sensing performance of $\mathrm{rGO} / \mathrm{ZnO}_{1-\mathrm{x}}$ nanocomposite towards $\mathrm{NO}_{2}$ gas with $100 \mathrm{ppb}$ concentration. (c) Sensor's selectivity towards $\mathrm{NO}_{2}(100 \mathrm{ppb})$ in comparison with $\mathrm{SO}_{2}(100 \mathrm{ppm}), \mathrm{H}_{2}(400 \mathrm{ppm})$, $\mathrm{HCHO}(10 \mathrm{ppm}), \mathrm{CO}(100 \mathrm{ppm}), \mathrm{NH}_{3}(100 \mathrm{ppm})$ under white light illumination at room temperature. Reproduced with permission from [26] Elsevier, 2019. (d) SEM images and (e) sensing response of hybrid $\mathrm{SnS}_{2}$-rGO sensor in the presence of 11.9 ppm $\mathrm{NO}_{2}$ as a function of operating temperatures. (f) Sensor selectivity towards $\mathrm{NO}_{2}(11.9 \mathrm{ppm}), \mathrm{NH}_{3}(99 \mathrm{ppm})$, ethanol (50 ppm), acetone (50.5 ppm), $\mathrm{CH}_{4}(10 \mathrm{ppm})$ at $50 \%$ relative humidity $(\mathrm{RH})$ and $80{ }^{\circ} \mathrm{C}$. Reproduced with permission from [30] Elsevier, 2018. Inset: band realignment and energy diagram of $\mathrm{SnS}_{2} / \mathrm{rGO}$ sensors.

In another approach, Shafiei et al. [30] developed a low operating temperature hybrid nanostructured gas sensor made of wet-synthesized $\mathrm{SnS}_{2}$ nanoflakes (Figure 1d) dropcasted on a rGO film. The synthesized $\mathrm{SnS}_{2}$ nanoflakes demonstrated a typical thickness of $6 \mathrm{~nm}$ (Figure 1d, inset) corresponding to only 10 monolayers of 2D hexagonal $\mathrm{SnS}_{2}$ flakes. The fabricated sensor deposited on the alumina substrates featuring Au-Ti interdigitated electrodes showed a strong sensing response of 0.85 towards $11.9 \mathrm{ppm} \mathrm{NO} \mathrm{NO}_{2}$ at a room temperature of $25{ }^{\circ} \mathrm{C}$. However, a long response time of $3.8 \mathrm{~min}$ was recorded while the sensor never recovered to the original baseline. Increasing the temperature to $80^{\circ} \mathrm{C}$, however, reduced the response to a magnitude of 0.57 with full recovery to the baseline resistance (Figure 1e). This reduced sensing response at higher operating temperature is attributed to the competition between adsorption and desorption of targeting gas on and from the surface, indicating the dominant effect of surface desorption of $\mathrm{NO}_{2}$ gas molecules [30]. Further increases in the operating temperature up to $100{ }^{\circ} \mathrm{C}$ resulted in only a negligible decrease in the response magnitude and response time (Figure 1e), while the recovery speed improved slightly.

In this case, the sensing mechanism is based on an electrostatic field formation at the interface between $\mathrm{SnS}_{2}$ and $\mathrm{rGO}$ due to the difference between work functions. This electric field results in the transfer of electrons from $\mathrm{rGO}$ to the surface of the $\mathrm{SnS}_{2}$ nanoflakes (Figure 1f, inset), leading to higher concentrations of electron and hole charges in the $\mathrm{SnS}_{2}$ 
and rGO films, respectively. Upon exposure to $\mathrm{NO}_{2}$ gas, an electron on the surface of $\mathrm{SnS}_{2}$ nanoflakes is captured by the gas molecules leading to the formation of negatively charged $\mathrm{NO}_{2}{ }^{-}$species (Figure 1f, inset), thereby causing a reduction in film resistance [18]. The response magnitude increased from 0.25 to 0.57 with increasing the $\mathrm{NO}_{2}$ gas concentration from 0.75 to $7.5 \mathrm{ppm}$. However, the response magnitude saturated with no further change in film resistance for the $\mathrm{NO}_{2}$ gas concentration higher than $7.5 \mathrm{ppm}$. The gas selectivity of the developed $\mathrm{SnS}_{2}$-rGO films were tested towards a variety of target gases including $\mathrm{NH}_{3}$ (ammonia), $\mathrm{C}_{2} \mathrm{H}_{6} \mathrm{O}$ (ethanol), $\mathrm{C}_{3} \mathrm{H}_{6} \mathrm{O}$ (acetone) and $\mathrm{CH}_{4}$ (methane). No detectable response was observed upon exposure to ethanol, acetone or methane (Figure 1f), demonstrating high selectivity of the film towards these gases while a low response of $12 \%$ was detected towards relatively high concentrations of $\mathrm{NH}_{3}$ (99 ppm) [30]. This selectivity towards $\mathrm{NO}_{2}$ could be attributed to the remarkably high molecular-surface binding energy $(140 \mathrm{meV})$ between the sensing material $\left(\mathrm{SnS}_{2}\right)$ and $\mathrm{NO}_{2}$ gas molecules, resulting in higher physisorption rate of $\mathrm{NO}_{2}$ gas molecules compared to other gases including $\mathrm{CH}_{4}, \mathrm{C}_{3} \mathrm{H}_{6} \mathrm{O}$ and $\mathrm{C}_{2} \mathrm{H}_{6} \mathrm{O}$ [31]. In a similar approach, $\mathrm{SnS}_{2} / \mathrm{rGO}$ nanohybrids were also fabricated by Huang et al. for ppb-level $\mathrm{NO}_{2}$ gas detection [18]. By tuning the ratio of $\mathrm{rGO}$ and $\mathrm{SnS}_{2}$, the sensors exhibited $\mathrm{p}$ - and n-type transitions with remarkable 1-5 ppb limit of detection (LOD) and fast response dynamics at room temperature (Table 1). A combination of visible light $\left(\lambda=650 \mathrm{~nm}, 1 \mathrm{~mW} \cdot \mathrm{cm}^{-2}\right)$ and a bias of $15 \mathrm{~V}$ was used to achieve the room temperature sensing performance [18].

\subsection{Sulphur Dioxide $\left(\mathrm{SO}_{2}\right)$}

$\mathrm{SO}_{2}$ is another air quality indicator listed in Air Quality Guidelines by the WHO [20], with a threshold limit of 5 ppm for human exposure and a long-term exposure limit of only 2 ppm [32,33]. It is a highly toxic gas with a pungent, irritating, and rotten smell. Natural phenomena such as volcanic eruptions, degradation of organic waste matter and hot springs, or human activities including burning of fossil fuels, metallurgical processing of pyrite and sulfide ores, etc., can result in releasing $\mathrm{SO}_{2}$ gas molecules into the atmosphere $[1,33]$. Inhalation of $\mathrm{SO}_{2}$ gas can seriously affect human health including irritation in respiratory tracts and eyes, bronchitis, asthma, permanent pulmonary impairment, and lung cancer [19]. Detection of $\mathrm{SO}_{2}$ is an important objective, but considering the corrosiveness of $\mathrm{SO}_{2}$ gas, developing a sensitive, selective, and reliable $\mathrm{SO}_{2}$ gas sensor for real time monitoring of $\mathrm{SO}_{2}$ molecules at room temperature is a significant challenge.

Zhao et al. [34] demonstrated an on-chip growth of ultrathin $\mathrm{Cu}$-doped $\mathrm{SnO}_{2}$ nanosheet arrays (Figure 2a, inset) using a homogenous precipitation method that produced vertically aligned flake-like nanosheets (Figure $2 b$, inset) with an average thickness of less than $10 \mathrm{~nm}$. Using $\mathrm{Cu}$ atoms as morphological modifier to generate structural defects, the optimal $1 \mathrm{~mol} \% \mathrm{Cu}-\mathrm{SnO}_{2}$ device showed a 90.15 sensing response toward $6 \mathrm{ppm} \mathrm{SO}_{2}$ compared to a 2.95 response in the case of pure $\mathrm{SnO}_{2}$, at the same $6 \mathrm{ppm} \mathrm{SO}$ concentration (Figure 2a). This higher sensing performance (23-fold) is attributed to the incorporation of $\mathrm{Cu}$ dopants into $\mathrm{SnO}_{2}$ lattice, the generation of a large concentrations of oxygen vacancies and consequently more adsorption sites in the $\mathrm{Cu}-\mathrm{SnO}_{2}$ nanostructure [34]. Further increase in the $\mathrm{Cu}$ dopant concentration up to $5 \mathrm{~mol} \%$, however, reduced the sensor's response significantly to 10.82 (Figure $2 \mathrm{a}$ ). This lower sensing performance could be ascribed to the reduction in the available surface area due to the formation of irregular shaped particles within the nanostructure. However, more studies are required to provide a clear understanding on the key role that a particle shape might play in changing the sensing performance of nanostructured devices. In addition, high operating temperature $\left(250^{\circ} \mathrm{C}\right)$ and excessive energy consumption hinders real-world application as portable gas sensors. Optimization of the working temperature is an important functional characteristic as temperature controls the adsorption-desorption equilibrium of the gases at the surface of the sensor, diffusion of the gases, formation and surface density of oxygenated anionic species, and the electronic mobility between the conduction and the valence band of the semiconductor metal oxides [35]. 

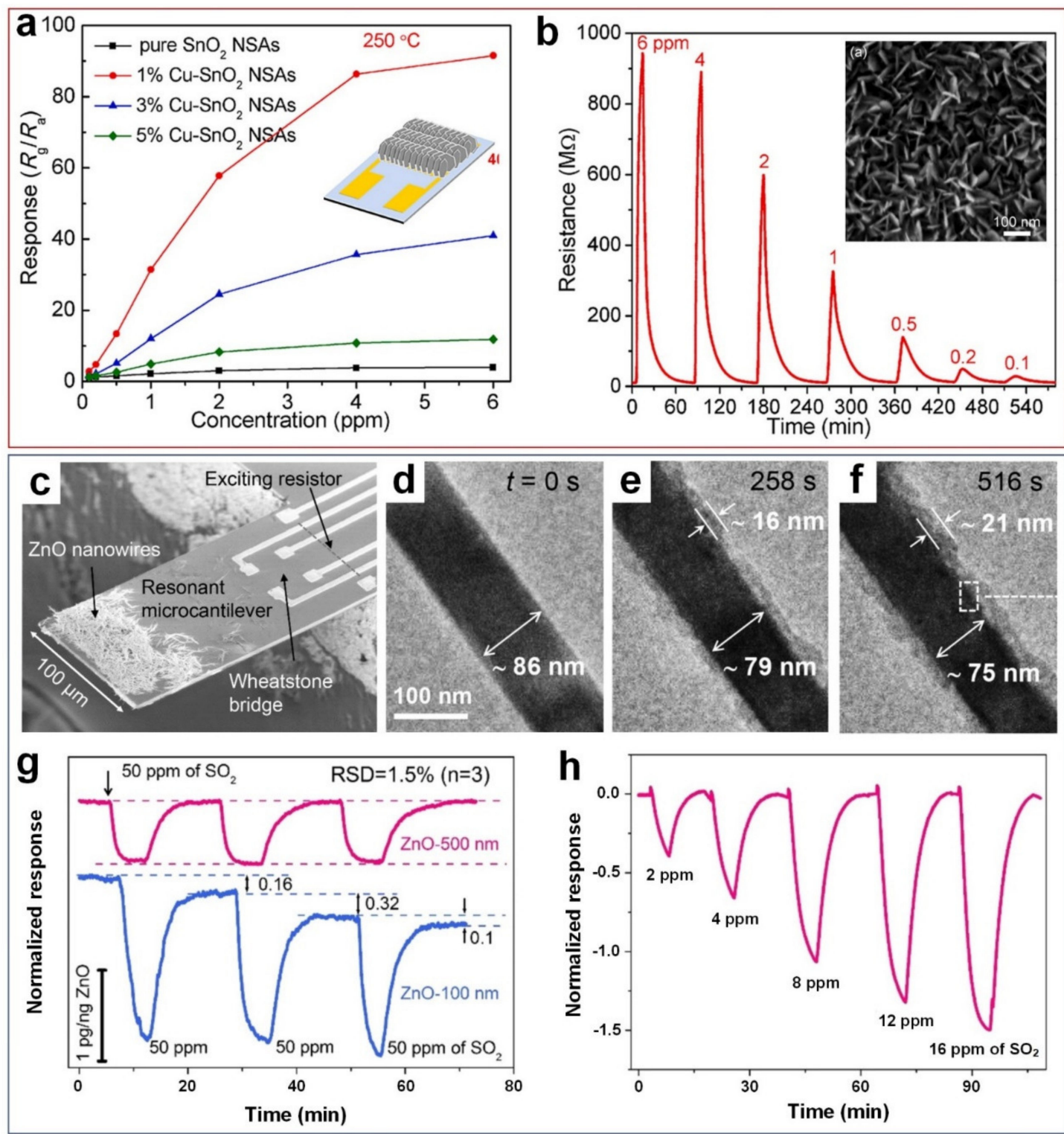

Figure 2. (a) Sensing response of $\mathrm{Cu}$-doped $\mathrm{SnO}_{2}$ sensors with different $\mathrm{Cu}$ content and (b) the corresponding dynamic resistance curves of $1 \% \mathrm{Cu}$-doped sensors toward $\mathrm{SO}_{2}$ with concentrations of $0.1-6 \mathrm{ppm}$ at $250{ }^{\circ} \mathrm{C}$ (inset: the SEM image $1 \% \mathrm{Cu}-\mathrm{SnO}_{2}$ sensor). Reproduced with permission from [34] Elsevier, 2020. (c) SEM image of on the resonant microcantilever loaded with $\mathrm{ZnO}$ nanowires. (d-f) In-situ TEM of the $\mathrm{ZnO}-100 \mathrm{~nm}$ sample surface morphology with the presence of $\mathrm{SO}_{2}$ gas for different exposure time. (g) The sensing dynamics of the $\mathrm{ZnO} 100 \mathrm{~nm}$ and $500 \mathrm{~nm}$ samples to $\mathrm{SO}_{2}$ gas. (h) The sensing performance of $\mathrm{ZnO}-500 \mathrm{~nm}$ sensor to different concentration of $\mathrm{SO}_{2}$ gas at $30{ }^{\circ} \mathrm{C}$. Reproduced with permission from [36] American Chemical Society, 2021.

Despite significant progress in developing chemiresistive metal-oxide semiconductorbased gas sensors for $\mathrm{SO}_{2}$ gas detection, irreversible reactions between $\mathrm{SO}_{2}$ gas molecules and metal oxide sensing materials hinder their room temperature application as a prolonged UV irradiation and heating process is required to recover the sensor to the baseline. Using a solvothermal fabrication technique, Nikesh et al. [33] developed a p-type field effect transistor (FET) based on a nanocomposite made of nickel benzene carboxylic $\left(\mathrm{Ni}_{3} \mathrm{BTC}_{2}\right)$ and $\mathrm{OH}$-functionalized single-walled carbon nanotube (OH-SWNTs) for reversable detection of $\mathrm{SO}_{2}$ gas (4-20 ppm) at room temperature. However, further investigation is required to fully understand the sensing mechanism and the reversibility of such nanocomposites.

In another study, Wang et al. [36] demonstrated a quantitative analysis of kinetics of solid-gas reactions between $\mathrm{ZnO}$ nanowires and $\mathrm{SO}_{2}$ gas molecules using in situ TEM 
technique (Figure 2c) and recorded the real-time morphological evolution of the $\mathrm{ZnO}$ nanowires during $\mathrm{SO}_{2}$ gas exposure. When the experiment was carried out at room temperature, no obvious morphology change was observed, and the morphology change only occurred when the temperature was increased to $70{ }^{\circ} \mathrm{C}$ [36]. As shown in Figure $2 \mathrm{~d}-\mathrm{f}$, a homogenous shell gradually formed on the outer layer of $\mathrm{ZnO}-100 \mathrm{~nm}$ nanowire due to the diffusion of $\mathrm{SO}_{2}$ molecules through the $\mathrm{ZnO}$ surface where the shell thickness increased from 0 to $16 \mathrm{~nm}$ by increasing the exposure time from 0 to $258 \mathrm{~s}$. This is attributed to the irreversible reaction between $\mathrm{SO}_{2}$ gas molecules and $\mathrm{ZnO}$ surface where atoms on the nanowires surface were gradually consumed by $\mathrm{SO}_{2}$ to form a zinc sulfite hydrate $\left(\mathrm{ZnSO}_{3} \cdot 2.5 \mathrm{H}_{2} \mathrm{O}\right)$ shell [36]. Further increase in the exposure time up to $516 \mathrm{~s}$ led to the formation of a dense shell layer $(21 \mathrm{~nm}$ ) around the $\mathrm{ZnO}$ surface (Figure 2f), resulting in the slower reaction rate between $\mathrm{SO}_{2}$ gas molecules and atoms on the $\mathrm{ZnO}$ surface.

A different solid-gas reaction kinetic, however, was observed for $\mathrm{ZnO}$ nanowires with $500 \mathrm{~nm}$ diameter where no obvious morphological change on the smooth surface of the $\mathrm{ZnO}$ nanowires over exposure to $\mathrm{SO}_{2}$ gas molecules even hours after the reaction was completed. Figure $2 \mathrm{~g}$ illustrates the sensing response of $\mathrm{ZnO}-100 \mathrm{~nm}$ and $\mathrm{ZnO}-500 \mathrm{~nm}$ nanowires towards $50 \mathrm{ppm}$ of $\mathrm{SO}_{2}$ gas molecules at $70{ }^{\circ} \mathrm{C}$. The $\mathrm{ZnO}-100 \mathrm{~nm}$ sample exhibited higher sensing response values than the $\mathrm{ZnO}-500 \mathrm{~nm}$ sample. However, the sensing material never recovered to the baseline (Figure $2 \mathrm{~g}$, blue line). In fact, the high reactivity of the $\mathrm{ZnO}-100 \mathrm{~nm}$ sample towards $\mathrm{SO}_{2}$ gas is due to the poisoning effect of $\mathrm{SO}_{2}$ on $\mathrm{ZnO}$ surface, and consequently, irreversible solid-gas reaction between thin nanowires and gas molecules [36]. In contrast, a reversible sensing response to $\mathrm{SO}_{2}$ was observed for the $\mathrm{ZnO}-500 \mathrm{~nm}$ nanowires (Figure 2g, pink line), indicating the important role nanostructures play in solid-gas reaction kinetics where $\mathrm{ZnO}-500 \mathrm{~nm}$ is a suitable sample as a reversable $\mathrm{SO}_{2}$ sensing material while (Figure $2 \mathrm{~h}$ ) $\mathrm{ZnO}-100 \mathrm{~nm}$ could be used in $\mathrm{SO}_{2}$ gas capturing applications. Figure $2 \mathrm{~h}$ presents the normalized sensing performance of fabricated $\mathrm{ZnO}-500 \mathrm{~nm}$ nanowires towards $\mathrm{SO}_{2}$ gas in a concentration range of 2-16 ppm, at low operating temperature of $30^{\circ} \mathrm{C}$. The experimentally observed LOD towards detecting $\mathrm{SO}_{2}$ gas molecules was lower than $2 \mathrm{ppm}$ for $\mathrm{ZnO}-500 \mathrm{~nm}$ nanowires. A LOD of $70 \mathrm{ppb}$ was reported using the empirical method and a signal-to-noise ratio of 3 [36].

\subsection{Carbon Dioxide $\left(\mathrm{CO}_{2}\right)$}

$\mathrm{CO}_{2}$ is an odorless, colorless and an important long-lived trace gas that now constitutes up to around $0.04 \mathrm{~mol} \%$ (415 ppm) of the atmosphere [37]. Despite its relatively small overall concentration, $\mathrm{CO}_{2}$ is the major primary driver of climate change among all different types of greenhouse gases [38]. Human emission of $\mathrm{CO}_{2}$ has increased significantly since preindustrial times [39], which will potentially cause irreversible damages to the environment in the next coming years [40]. In addition, sustained $\mathrm{CO}_{2}$ exposure in indoors settings can cause inflammation, reduction in cognitive abilities and oxidative stress at modest concentration levels (1000 ppm) [41,42]. Many countries have pledged carbon neutrality within the upcoming three decades; the design and fabrication of a stable, reversible, real-time $\mathrm{CO}_{2}$ gas sensor with fast response dynamics, ppm level detection and low cost that could be easily deployed in urban cites will greatly assist a pathway towards lower and net-zero $\mathrm{CO}_{2}$ emissions [43].

Current sensing technologies to monitor atmospheric concentration of $\mathrm{CO}_{2}$ is based on nondispersive infrared (NDIR) sensors where an IR lamp guides light waves through a sampling tube filled with atmospheric air. The difference between the wavelengths radiated by lamp and the wavelengths absorbed by the detector is used as an indicator for $\mathrm{CO}_{2}$ gas concentration. In such sensing systems, an optical filter is placed in front of an IR detector which absorbs all wavelengths generated by the IR lamp, except the ones which are absorbed by $\mathrm{CO}_{2}$ molecules. NDIR-based sensors demonstrate acceptable sensitivity and fast response towards a broad $\mathrm{CO}_{2}$ concentration range. However, their high-power consumption hinders their utilization in battery-driven devices. Several detection techniques including surface plasmon resonance, surface acoustic wave, fluo- 
rescent and colorimetric sensing technologies have been used to develop highly sensitive and selective $\mathrm{CO}_{2}$ gas sensors that can operate at ambient temperatures [44]. However, there are still many challenges that restrict the commercial availability of these sensing devices including high complexity of the structural configuration, its large size and high cost [44]. Recently, hollow nanostructures have attracted much attention as promising nano-designed gas sensors due to their unique porous morphology, high specific surface area and effective gas diffusion [45-47]. Using a simple microwave-assisted solvothermal method (Figure 3a), Zito et al. [48] developed yolk-shell $\mathrm{CeO}_{2}$ nanospheres with an average nanosphere diameter of $190 \pm 20 \mathrm{~nm}$ (Figure 3b-e), demonstrating an efficient strategy to enhance the sensing performance of metal oxide nanosensors towards $\mathrm{CO}_{2}$ gas. At a relatively low temperature $\left(100^{\circ} \mathrm{C}\right)$ and relative humidity of $70 \%$, a high gas response of 2.9 with a fast response and recovery times of $2.58 \mathrm{~min}$ and $4.08 \mathrm{~min}$, respectively, was reported for the yolk-shell $\mathrm{CeO}_{2}$ nanospheres towards $2400 \mathrm{ppm} \mathrm{CO}_{2}$ gas, compared to a sensing response of 0.4 for the commercial $\mathrm{CeO}_{2}$ nanoparticles (Figure $3 \mathrm{~h}$ ). This higher sensing performance is attributed to the higher surface area and porosity of the yolk-shell nanosphere, enhancing the permeability to gas adsorption even into the inner part of the nanospheres [47]. Compared to the bulky and impermeable structure of the commercial $\mathrm{CeO}_{2}$, this porous nanostructure plays a vital role in providing an effective carrier gas diffusion after $\mathrm{CO}_{2}$ pulses, thereby enhancing the recovery speed of the sensing material (Figure $3 \mathrm{f}, \mathrm{g}$ ). This results in a full recovery of yolk-shell nanostructured morphology, compared to partial recovery of commercial $\mathrm{CeO}_{2}$, avoiding the formation of any drift in the baseline resistance between gas pulses (Figure 3f,g).
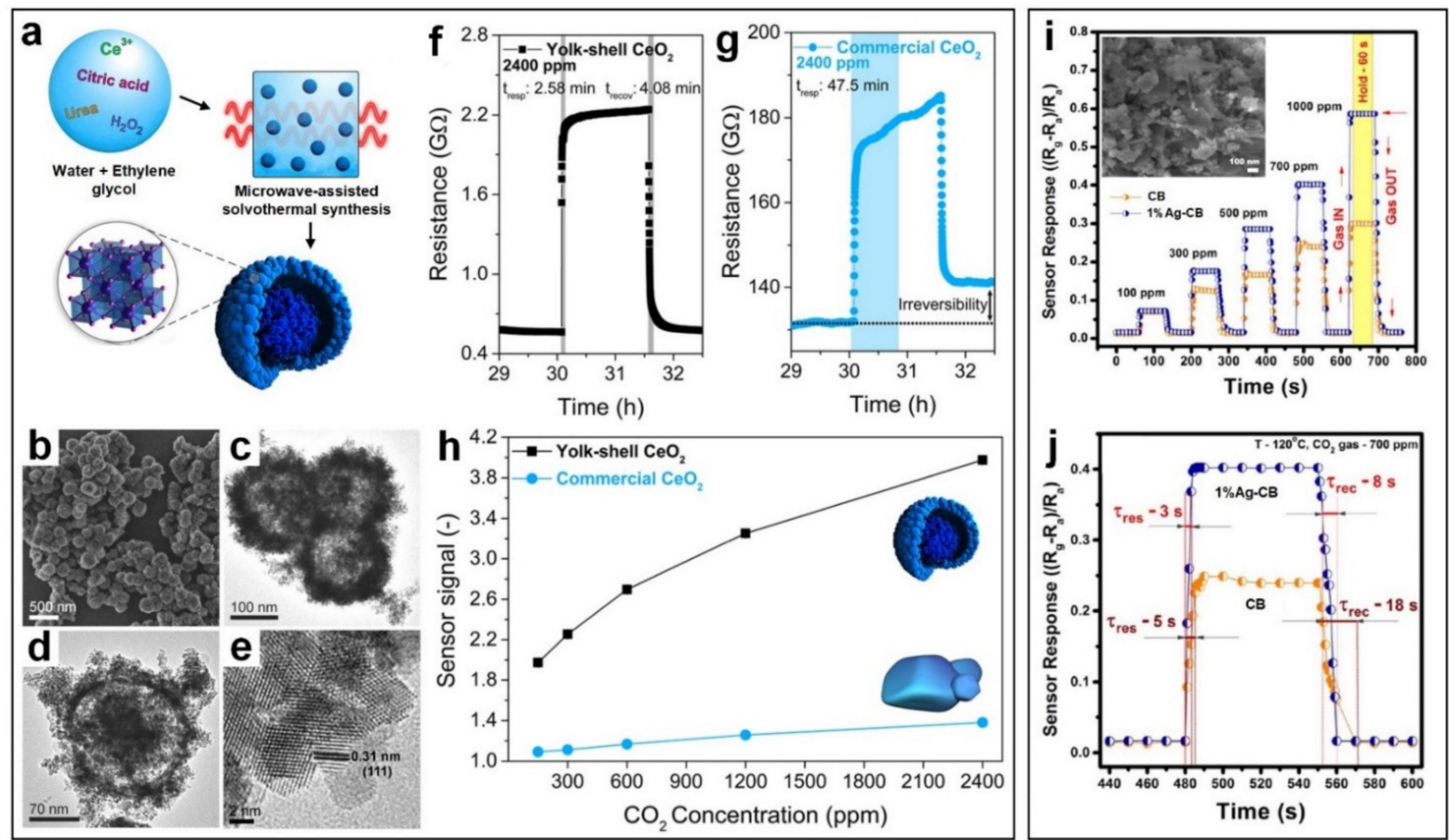

Figure 3. (a) Schematic illustration of the microwave-assisted solvothermal synthesis of the yolk-shell $\mathrm{CeO}_{2}$ nanospheres. (b) FESEM and (c-e) TEM images of yolk-shell $\mathrm{CeO}_{2}$ nanospheres. $(\mathbf{f}, \mathbf{g})$ Response and recovery times of the yolk-shell $\mathrm{CeO}_{2}$ and commercial $\mathrm{CeO}_{2}$ nanosensors towards $2400 \mathrm{ppm}$ of $\mathrm{CO}_{2}$. (h) Sensor signal of the yolk-shell and commercial $\mathrm{CeO}_{2}$ nanospheres as a function of $\mathrm{CO}_{2}$ concentration. Reproduced with permission from [48] American Chemical Society, 2020. (i) Response dynamic transients of the $\mathrm{Ag} @ \mathrm{CuO} / \mathrm{BaTiO}_{3}$ sensor as a function of $\mathrm{CO}_{2}$ concentration at $120^{\circ} \mathrm{C}$ (inset: $\mathrm{BaTiO}_{3}$ spheroids decorated with $\mathrm{CuO}$ microleaves in the equimolar ratio). (j) Comparative response and recovery curve of $700 \mathrm{ppm} \mathrm{CO}_{2}$ gas at $120^{\circ} \mathrm{C}$. Reproduced with permission from [49] American Chemical Society, 2017. 
In another approach, a hybrid heterostructure made of tetragonal n-type $\mathrm{BaTiO}_{3}$ spheroids decorated with p-type $\mathrm{CuO}$ micro-leaves (Figure $3 \mathrm{i}$, inset) was synthesized by a simple hydrothermal method [49], demonstrating an exceptional stability and sensitivity toward $\mathrm{CO}_{2}$ gas compared to pure $\mathrm{BaTiO}_{3}$ device (Figure 3i). The $\mathrm{BaTiO}_{3}$ has a large bandgap of 3.1-3.3 eV with a high carrier concentration of up to $7 \times 10^{21} \mathrm{~cm}^{-3}$ with minimal lattice mismatch with $\mathrm{CuO}(<2 \%)$, making them promising pairs for the formation of hybrid heterostructure [50,51]. The $\mathrm{p}-\mathrm{n}$ junction formation results in creating electronic interaction and change in work function of sensing materials, which leads to reduction in the energy barrier at the grain boundary of $\mathrm{BaTiO}_{3}$ and $\mathrm{CuO}$ [49]. This leads to the formation of a smaller depletion layer and subsequently, higher sensing response upon exposure to $\mathrm{CO}_{2}$ gas molecules. The sensing mechanism is based on a reversible reaction between $\mathrm{CuO}$ and $\mathrm{CO}_{2}$ gas resulting in the formation of copper hydroxycarbonates [49]. Further improvement in sensing response of the fabricated $\mathrm{p}-\mathrm{n}$ heterojunction material was achieved by incorporation of Ag nanoparticles via wet impregnation. This higher sensing performance could be attributed to the partial oxidization of Ag nanoparticles and the formation of thin $\mathrm{Ag}_{2} \mathrm{O}$ layers which could act as acceptors, facilitating the sensing phenomenon towards $\mathrm{CO}_{2}$ gas [49]. In addition, the $\mathrm{p}-n$ junction-based sensor coated with Ag nanoparticles showed a fast response and recovery time of less than $10 \mathrm{~s}$ (Figure 3j), demonstrating a promising sensing performance for real-time detection of $\mathrm{CO}_{2}$ gas at low operating temperature of $120^{\circ} \mathrm{C}$.

Recently, the combination of organic polymers and allotropes of carbon (graphene and SWCNTs) was used to reduce the operating temperature down to room temperature for $\mathrm{CO}_{2}$ gas detection at a relatively high concentrations (5000 ppm, 2\%). Son et al. [52] reported an amine-rich polyethyleneimine (PEI)/graphene organic-inorganic hybrid sensor for fast $\mathrm{CO}_{2}$ sensing, demonstrating a high sensing response of $32 \%$ compared to $0.4 \%$ for PEI-functionalized graphene. A very low bias of $0.1 \mathrm{~V}$ was applied during the gas sensing process, resulting in a remarkable "several tens of seconds" for both response and recovery time [52]. Yoon et al. [53] developed a polymer-based chemiresisitve $\mathrm{CO}_{2}$ sensor by anchoring a precursor copolymer bearing both 4-vinylpyridine (4VP) groups and azide groups on the surface of SWCNTs resulting in a response of $25 \%$ at room temperature for $2 \% \mathrm{CO}_{2}$ concentration. However, a very long response time of several thousand of seconds was recorded, where full recovery to the baseline never achieved at room temperature. Further studies are required to the sensing performance of organic-inorganic hybrid sensors towards practical $\mathrm{CO}_{2}$ gas sensing application [37].

\section{Health and Medical Monitoring}

Breath analysis is an emerging field of medical diagnostics that promises a rapid, real-time, non-invasive, and cost-effective alternative to monitoring techniques such as blood analysis, endoscopy, ultrasonic and tomographic monitoring [54]. VOCs in human breath can reveal a range of common illnesses such as asthma, kidney failure, lung cancer, diabetes, and heart disease. For example, ammonia, isoprene and acetone in the breath can be used to evaluate kidney malfunction, liver fibrosis, and diabetes, respectively [10,55].

\subsection{Ammonia $\left(\mathrm{NH}_{3}\right)$}

Ammonia is a corrosive, poisonous and toxic gas with unpleasant smell, which is widely used in various industries including fertilizer, pharmacy and fermentation [56,57]. It may cause burns to the eyes and skin, and respiratory system damage when the concentration is greater than $300 \mathrm{ppm}$ [58]. It is also a promising breath biomarker for detecting and monitoring kidney and liver disease $[59,60]$. The development of a non-invasive, flexible, reliable, robust and fast-response $\mathrm{NH}_{3}$ gas sensor operating at a low temperature is of great interest. However, most commonly used gas sensors are on a rigid substrate with no flexibility, and often operate at elevated temperatures (above $200{ }^{\circ} \mathrm{C}$ ), hindering their real-world applications as portable miniaturized gas sensors. On the other hand, if flexible substrates such as polydimethylsiloxane (PDMS) [61], cotton fabrics [62], foil [63] 
and paper [64] can be used, then the gas sensor itself can become lightweight and flexible and can be produced at large scale with the prospect of extensive high-value applications.

Recently, electrically conductive nanostructured polymers including polyaniline (PANI) have attracted much attention as potential chemiresistive gas sensors due to their high conductivity and strong response to specific gases. Cai et al. [65] developed a hierarchical nanostructured PANI-based gas sensor (Figure 4a) on a flexible substrate made of cyclic olefin copolymer (COC). The fabrication technique involved the deposition of the hierarchical PANI on a sacrificial $\mathrm{Cu}$ micromesh template (Figure $4 \mathrm{a}(\mathrm{i}, \mathrm{ii})$ ) and removal of excess residual (Figure $4 \mathrm{a}(\mathrm{iii})$ ) resulting in the development of hexagonal PANI micromesh sensor embedded in the flexible COC film (Figure $4 \mathrm{a}(\mathrm{iv})$ ). The SEM images of Cu mesh, the PANI mesh after 3- and 20-min polymerization are presented in Figure $4 \mathrm{~b}-\mathrm{d}$. The device featured superior sensitivity towards $\mathrm{NH}_{3}$ with a sensing response of 0.7 to $100 \mathrm{ppb}$ at room temperature (Figure 4e) compared to negligible response from PANI film and $\mathrm{Cu}$ mesh. This excellent sensing response is attributed to the surface roughness as well as increased specific surface area for the PANI mesh compared to the smoother surface on the PANI film. In addition, the presence of catalytic $\mathrm{Cu}$ ions in the PANI mesh resulted in the deposition of emeraldine salt of PANI, leading to higher resistance in the sensors and consequently, a higher response after exposure to $\mathrm{NH}_{3}$ gas molecules. The sensing mechanism is based on the chemical absorption of $\mathrm{NH}_{3}$ gas molecules on the surface of PANI polymer at room temperature, resulting in lower conductivity of the PANI mesh by a reversible transition from the emeraldine salt to its emeraldine base.
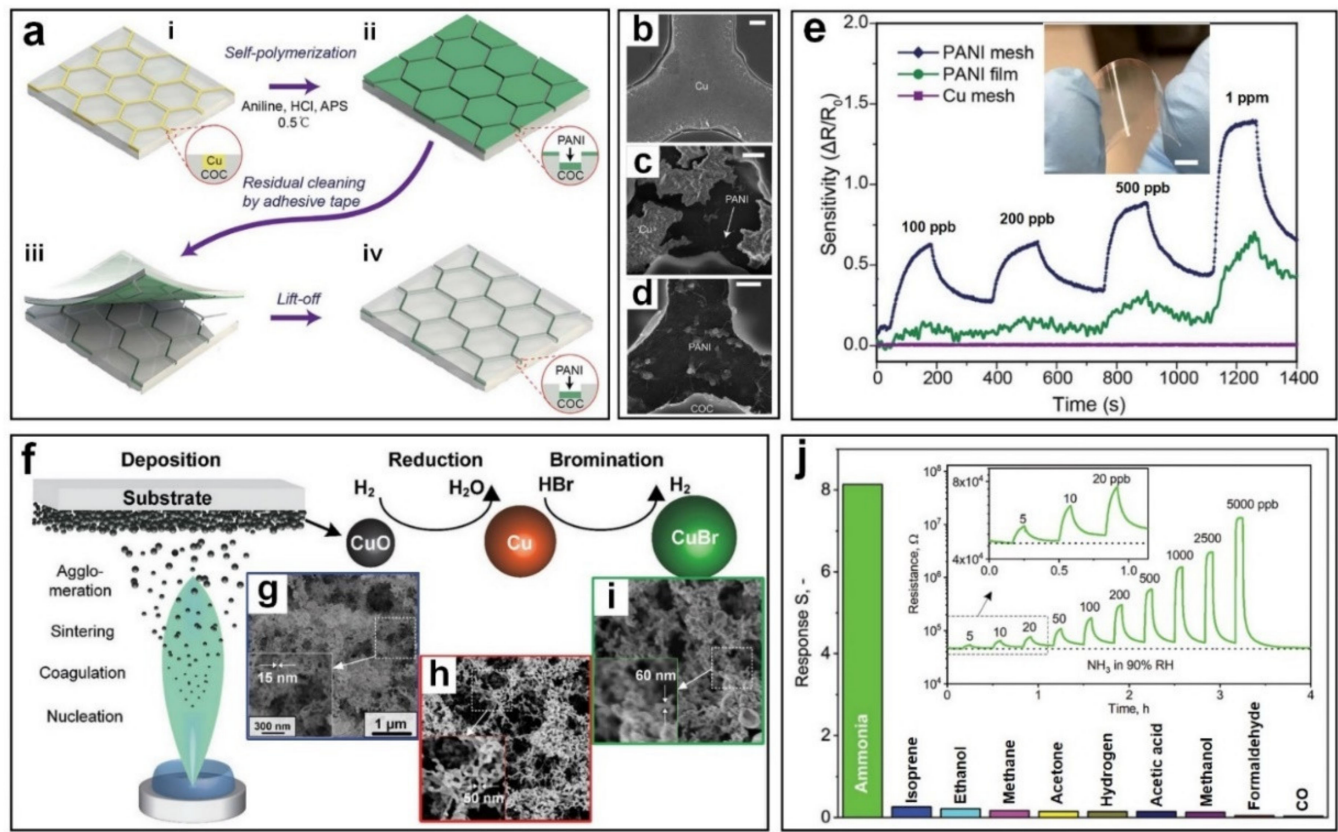

Figure 4. (a) The schematic illustrations of PANI mesh preparation. (a-i) The sacrificial Cu mesh template; (a-ii) deposition of the hierarchical PANI micromesh on the $\mathrm{Cu}$ template via in situ oxidative polymerization of aniline; (a-iii) removal of the excess residual PANI molecules from the exposed COC by adhesive tape; and (a-iv) a hexagonal hierarchical PANI micromesh embedded in the COC film. (b-d) SEM images of the original hexagonal $\mathrm{Cu}$ mesh and the PANI mesh after 3 min and $20 \mathrm{~min}$ in the aniline polymerization solution, respectively (scale bar is $1 \mu \mathrm{m}$ ). (e) The sensing performance of the $\mathrm{Cu}$ mesh, PANI film and PANI mesh with different concentrations of ammonia gas ranging from $100 \mathrm{ppb}$ to $1000 \mathrm{ppb}$. (Inset: the photograph of the transparent PANI mesh ammonia gas sensor). Reproduced with permission from [64,65] Royal Society of Chemistry, 2018. (f) Schematic of the CuBr gas sensing film fabricated via flame-aerosol deposition and dry conversion. Inset: SEM images the fractal-like $\mathrm{CuO}$ agglomerates after flame-Aerosol Deposition (g), lace-like $\mathrm{Cu}$ film with more macropores after the dry reduction (h) and preserved porous and open morphology of CuBr film after bromination (i). (j) Sensitivity performance comparison of $\mathrm{CuBr}$ films to $500 \mathrm{ppb}$ different gases at $90 \% \mathrm{RH}$. Inset: Sensing response of the dry-converted $\mathrm{CuBr}$ films to different $\mathrm{NH}_{3}$ concentrations at 90\% RH. Reproduced with permission from [65,66] Wiley-VCH, 2020. 
In another approach, a room-temperature, flexible $\mathrm{NH}_{3}$ gas sensor was fabricated by functionalizing the surface of polyethylene terephthalate (PET) fibers with amino group $\left(-\mathrm{NH}_{2}\right)$ followed by PANI coating [67]. A fast response dynamic of $47 \mathrm{~s}$ was achieved towards $50 \mathrm{ppm}$ of $\mathrm{NH}_{3}$ gas with the sensing response of 1.17. However, poor longterm stability was reported due to degradation of the sensing materials over a week testing period. Similar stability issue was reported for $\mathrm{SnO}_{2} /$ PANI nanocomposites due to PANI film aging over time [68]. Further investigation in PANI structural modification or seeking alternative polymers may resolve the reduced sensing performance due to polymer degradation.

In addition, the flexible substrate and the embedded PANI mesh (Figure 4e, inset) exhibited acceptable mechanical properties against peeling and bending with less than $15 \%$ reduction in the sensing performance after 1000 bending cycles. A low detection limit of $2.5 \mathrm{ppb}$ was observed for this PANI mesh sensor, making this polymer a strong candidate for low concentration detection of $\mathrm{NH}_{3}$ gas. However, slow recovery speeds will hinder real-world application as a reliable room temperature gas sensor.

In another approach, sub-ppb detection of $\mathrm{NH}_{3}$ gas molecules (down to $5 \mathrm{ppb}$ ) at $90 \% \mathrm{RH}$ and room temperature with fast response and recovery speed were reported using highly porous (78\% porosity) nanostructured $\mathrm{CuBr}$ films [66] (Figure 4f). The sensing film was fabricated by continuous deposition of $\mathrm{CuO}$ nanoparticles onto $\mathrm{Al}_{2} \mathrm{O}_{3}$ substrates as ultraporous metal oxide film (Figure $4 \mathrm{~g}$ ), followed by dry reduction of $\mathrm{CuO}$ to $\mathrm{Cu}$ using $\mathrm{H}_{2}$ gas (Figure 4h) and then bromination of $\mathrm{Cu}$ to $\mathrm{CuBr}$ with $\mathrm{HB}_{2}$ at $180{ }^{\circ} \mathrm{C}$ (Figure 4i). These CuBr films featured an excellent sensing response of 1 towards $10 \mathrm{ppb} \mathrm{NH}_{3}$ gas (Figure 4j, inset) and a fast response dynamic of $2.2 \mathrm{~min}$ and $50 \mathrm{~s}$ for response and recovery time respectively, which is outstanding for room temperature gas sensors at high relative humidity $(90 \% \mathrm{RH})$. This excellent sensing response is attributed to the unique properties of the fabricated film with $78 \%$ porosity and large surface area (Figure $4 \mathrm{i}$,) compared to the conventional $\mathrm{CuBr}$ film with a porosity $<40 \%$, facilitating rapid gas transport through the ultraporous nanostructure resulting in enhanced resistance modulation. The selectivity of this porous $\mathrm{CuBr}$ film was also tested towards other gases including hydrogen, acetone and carbon monoxide, resulting in excellent selectivity towards $\mathrm{NH}_{3}$ with a selectivity of higher than 30 which is superior to most state-of-the-art $\mathrm{NH}_{3}$ gas sensors. (Figure 4j).

\subsection{Isoprene $\left(\mathrm{C}_{5} \mathrm{H}_{8}\right)$}

Isoprene is a breath biomarker that could be used to quickly screen individuals for high blood cholesterol [69]. Healthy adults exhale a concentration of 22 to $234 \mathrm{ppb}$ isoprene $[70,71]$, however, patients with high cholesterol exhale much less. It is reported that the concentration of isoprene in human breath decreases by $~ 35 \%$ when patients are treated with cholesterol-lowering lova and atorvastatins [69]. Similar changes were reported in the breath composition of patients with lung cancer [71,72] and liver disease [73], indicating the importance of isoprene sensors in medical applications. The challenge, however, is to find a suitable material capable of detecting low concentration of isoprene sufficiently at high relative humidity and low operating temperature without any interference from other breath compounds.

Using flame spray pyrolysis, Guntner et al. [70] presented an isoprene selective chemiresistive sensor made of Ti-doped $\mathrm{ZnO}$ nanoparticles (with an average particle size of $20 \mathrm{~nm}$ ) forming an ultraporous nanostructured film. A superior isoprene response of 0.82 towards $500 \mathrm{ppb}$ was observed at an optimal Ti content of $2.5 \mathrm{~mol} \%$ at $90 \% \mathrm{RH}$ and an operating temperature of $325^{\circ} \mathrm{C}$. The excellent sensing performance at such a high relative humidity is attributed to substantial incorporation of $\mathrm{Ti}^{4+}$ cations into the $\mathrm{ZnO}$ wurtzite lattice, creating point detects in the crystal and impeding nanoparticle growth during flame synthesis. In addition, $\mathrm{Ti}^{4+}$ sites dissociate water and chemisorb the resulting hydroxyl groups that interact with isoprene, enhance the sensitivity and selectivity of Ti-doped $\mathrm{ZnO}$ isoprene gas sensors at $90 \% \mathrm{RH}$ compared to pure $\mathrm{ZnO}$ nanostructured sensors. 
Very recently, Noriko et al. [74] reported a highly sensitive isoprene gas sensor using pyramid shaped $\mathrm{ZnO}$ particles loaded by Au nanoparticles ( $3 \mathrm{~nm}$ in diameter) and synthesized via solvothermal method followed by $4 \mathrm{~h}$ annealing at $425^{\circ} \mathrm{C}$. The fabricated sensing material demonstrated a sensing response of 0.79 towards low concentrations of isoprene (50 ppb) under $80 \% \mathrm{RH}$ at $350^{\circ} \mathrm{C}$. Enhanced selectivity compared to acetone, ethanol and hydrogen was confirmed in Au-doped samples with an estimated detection limit of $6 \mathrm{ppb}$, which meets the requirements for diagnosis of liver disease and sleeping state by breath analysis [69]. However, its high operating temperature of $350^{\circ} \mathrm{C}$ currently required would restrict the commercial viability of this approach.

In order to reduce the operating temperature, Han et al. [75] developed a flowerlike $\mathrm{In}_{2} \mathrm{O}_{3}$ nanostructure using a simple hydrothermal technique, to detect isoprene gas molecules with a very low concentration $(5 \mathrm{ppb})$ at $190^{\circ} \mathrm{C}$. The nanostructure exhibited excellent long-term stability and a quick response dynamic with response time of $53 \mathrm{~s}$. This relatively low operating temperature $\left(190^{\circ} \mathrm{C}\right)$ extends the working life and facilitates the portable application of the sensor. However, further studies are required to investigate the sensor's selectivity towards isoprene upon exposure to a complex gas mixture as achieving a high selectivity towards the targeted gas is still one of the major challenges restricting the applications of metal oxide-based gas sensors. This challenge is more significant regarding isoprene detection due to the absence of distinct functional groups that can be exploited for selective sensor interaction.

An activated alumina filter with a high surface area adsorbent was used to enhance the selectivity of Pt-doped $\mathrm{SnO}_{2}$ sensors towards hydrophobic isoprene gas by adsorbing and retaining hydrophilic gaseous molecules in a gas mixture (Figure 5a) [76]. Using this technology, the hydrophilic gases including acetone, ethanol, methanol and ammonia were retained by the activated alumina filter while isoprene molecules with hydrophobic properties were passed unhindered. This innovative approach resulted in outstanding selectivity of $>100$ towards low concentration isoprene (down to $5 \mathrm{ppb}$ ) in a complex gas mixture at $90 \%$ RH (Figure $5 b, c$ ). The filter-based sensing technology featured great stability in sensing performance even after 8 days of continuous gas exposure. However, this Pt-doped $\mathrm{SnO}_{2}$ sensor needed to be maintained at $400{ }^{\circ} \mathrm{C}$ by a substrate back-heater during the whole process, a requirement that will result in high power consumption and shorter sensor lifetime. Meanwhile, the activated alumina filter may not work desirably for selective detection of isoprene in the presence of other hydrophobic gases in exhaled breath.

\subsection{Acetone $\left(\mathrm{C}_{3} \mathrm{H}_{6} \mathrm{O}\right)$}

Acetone concentrations in exhaled breath could be potentially indicated as a novel biomarker for non-blood based diabetic diagnostics and monitoring, specifically for Type I diabetes [77]. This is because a healthy individual exhales 300-900 ppb acetone gas, but the concentration can easily exceed $1800 \mathrm{ppb}$ for diabetes mellitus patients [78,79]. It was assessed that diabetes directly caused $4 \%$ of premature (under age 70 ) mortality from noncommunicable diseases (NCDs) [80], and the death toll is predicted to continue to double until 2030. The prevalence of diabetes mellitus is a worldwide issue, and the development of user-friendly portable non-invasive breath gas sensors would make a huge difference to patient outcomes. New materials and technologies that can be applied to detect the abnormality of acetone concentrations at an early stage of diabetes development, and the novel design of breath gas sensors that could offer a user-friendly monitoring features, such as portable non-invasive technologies, can greatly contribute to save more lives.

Despite significant progress in developing acetone sensing technologies, the sensitivity and detection limits of metal oxide semiconductor gas sensors at low temperatures are only in the range of sub-ppm $[81,82]$. Further improvements are required to enhance their sensitivity to $\mathrm{ppb}$ as well as high selectivity towards the targeted gas, particularly at low temperature and high relative humidity. A few materials have met the demands of $\mathrm{ppb}$ level detection for healthcare, but they were mostly decorated with noble metals [82] or incorporated minor metals [83-86], which is ideal for practical sensing devices. 

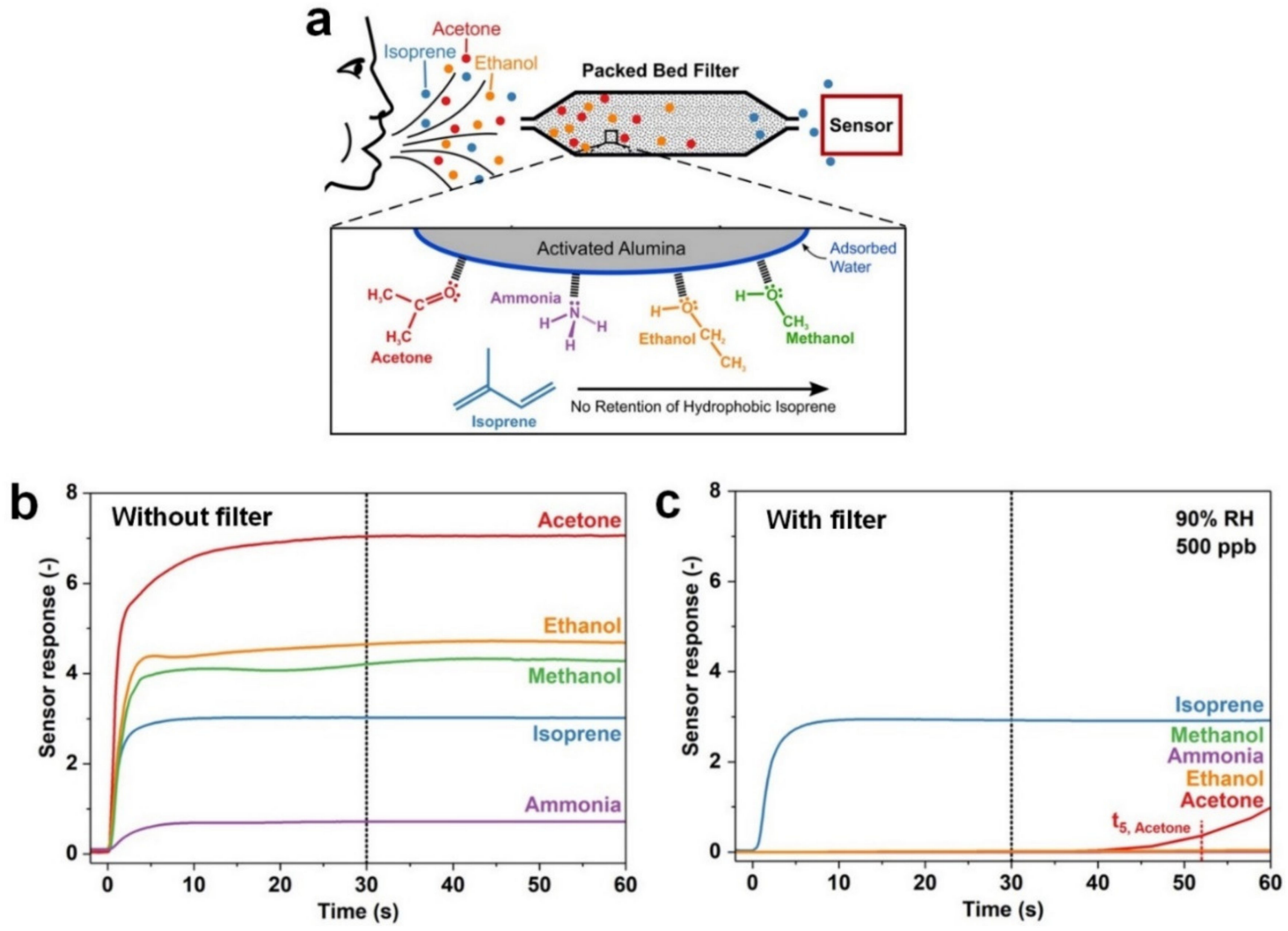

Figure 5. (a) Filter-sensing concept for selective isoprene detection in complex gas mixtures. Responses of a Pt-doped $\mathrm{SnO}_{2}$ sensor at $90 \% \mathrm{RH}$ to $500 \mathrm{ppb}$ of isoprene and other gases (b) without and (c) with activated alumina filter. Using the activated alumina filter, hydrophilic analytes are held back until their characteristic breakthrough time $t_{5}$, while the response of isoprene is unchanged. Reproduced with permission from [76] American Chemical Society, 2018.

Lu et al. [83] reported a fast responding ( $5 \mathrm{~s}$ response/recovery time) acetone gas sensor based on monoclinic and hexagonal phase of $\mathrm{WO}_{3}$ nanocrystalline fabricated by one-pot microwave assisted hydrothermal method. Increasing the operating temperature up to $320^{\circ} \mathrm{C}$ resulted in an outstanding sensitivity in ppb-level with a LOD of $7.5 \mathrm{ppb}$. This sensing performance could be attributed to the oxygen vacancies, different polarities from $\mathrm{WO}_{3}$ nanocrystalline geometry and the strong affinity between monoclinic $\mathrm{WO}_{3}$ and acetone molecules. However, its real-world application could be limited due to high operating temperature.

Lee et al. [46] developed a novel $\mathrm{p}-\mathrm{n}$ heterojunction chemiresistive sensor made of p-type $\mathrm{CuO}$ hollow nanocubes with an edge size of $15 \mathrm{~nm}$ attached to the surface of n-type $\mathrm{ZnO}$ spherical cores of $50 \mathrm{~nm}$ in diameter (Figure $6 \mathrm{a}, \mathrm{b}$ ). The fabricated $\mathrm{ZnO}-\mathrm{CuO}$ corehollow cube nanostructures presented a high sensing response of 10.14 towards $1 \mathrm{ppm}$ acetone concentration at $200{ }^{\circ} \mathrm{C}$ with a LOD of $9 \mathrm{ppb}$. This superior sensing response could be attributed to the unique morphology of these core-hollow nanostructures with excellent gas penetration through the active material, their small grain size ( 7 and $4 \mathrm{~nm}$ for $\mathrm{ZnO}$ and $\mathrm{CuO}$, respectively) and large surface area $\left(336 \mathrm{~m}^{2} \mathrm{~g}^{-1}\right)$.

The sensing mechanism is based on resistance modification through controlling the potential energy barrier at the interface and the narrowing of the conduction channel in fabricated $\mathrm{p}-\mathrm{n}$ junctions within the core-hollow nanostructure. Before treatment charge depletion layers were created at the $\mathrm{p}-\mathrm{n}$ junction interface, increasing the electrical resistance of the sensing materials. However, upon exposure to the acetone molecules, surface-adsorbed oxygen molecules react with the acetone, pushing the depletion layers into the $\mathrm{CuO}$ domains. The resistance eventually increases through the interparticle $\mathrm{p}-\mathrm{p}$ junctions, thus leading to such a high sensitivity and a low detection limit. However, there 
is still an increasing need to explore promising detection methods with the potential to provide outstanding acetone sensing at lower operating temperatures.
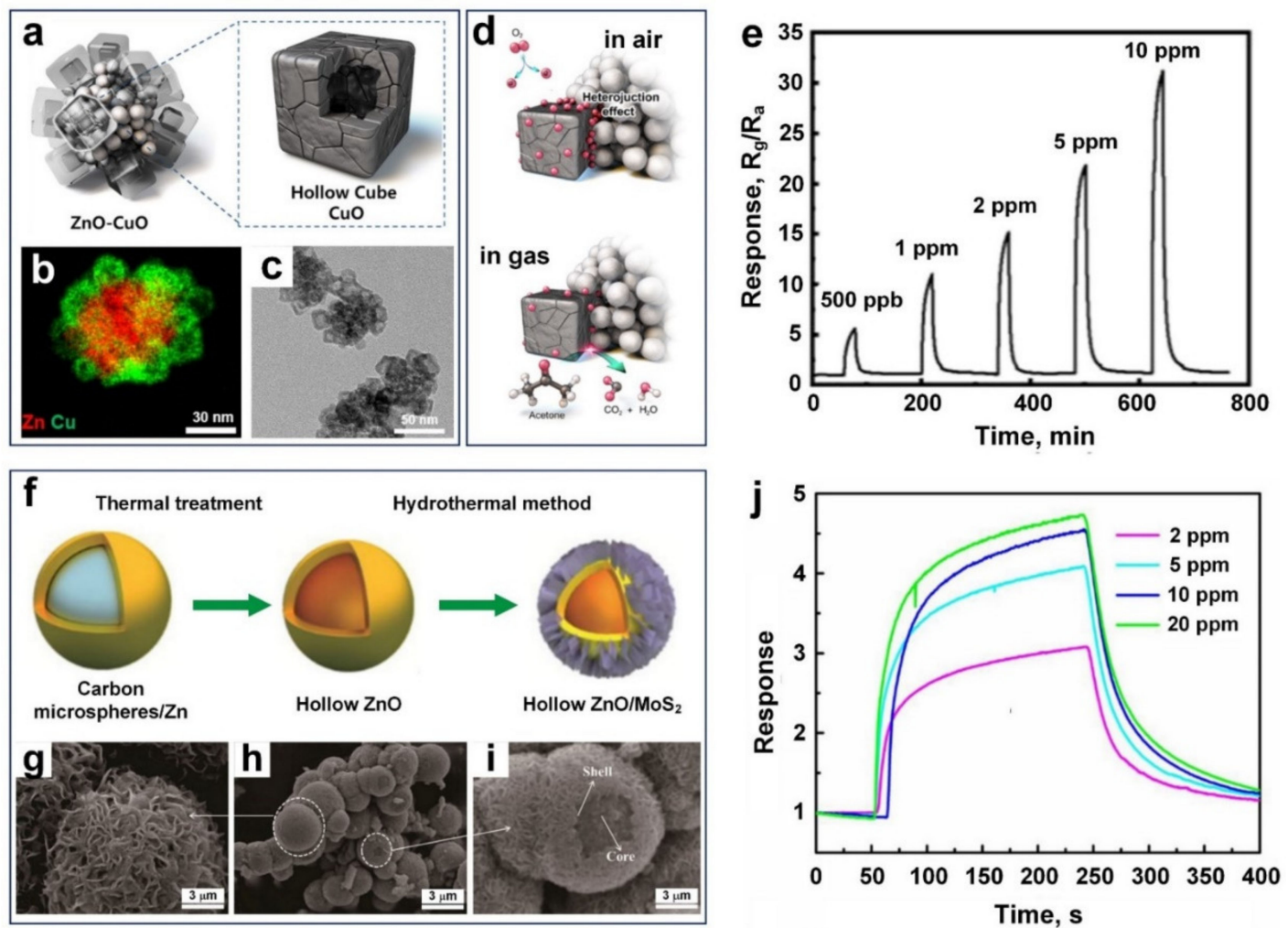

Figure 6. (a) Schematic, (b) elemental mapping, and (c) TEM image of the ZnO-CuO core-hollow cube nanostructures. (d) Schematic illustration of gas sensing mechanism upon exposure to acetone gas molecules. (e) Time-transient response curves of the sensors with a dynamic range of acetone concentrations at $200{ }^{\circ} \mathrm{C}$. Reproduced with permission from [46] American Chemical Society, 2020. (f) The schematic fabrication diagram, and (g-i) SEM images of $\mathrm{HZnO} / \mathrm{MoS} 2 \mathrm{core}_{\mathrm{shell}}$ heterogeneous structures. (j) The UV-assisted response dynamic of $\mathrm{HZnO} / \mathrm{MoS}_{2}$ to 2-20 ppm acetone gases. Reproduced with permission from [84] Elsevier, 2020.

Using a hydrothermal method, Chang et al. [84] developed a core-shell heterogenous structure made of hollow $\mathrm{ZnO}$ spheres with $40 \mathrm{~nm}$ wall thickness, and decorated by $2 \mathrm{D} \mathrm{MoS} 2$ nanosheets grown perpendicularly on the $\mathrm{ZnO}$ surface (Figure $6 \mathrm{f}-\mathrm{i}$ ). These nanoflower-shaped $\mathrm{MoS}_{2}$ nanosheets played a key role in protecting the hollow $\mathrm{ZnO}$ spheres from aggregation while accelerating gas diffusion through sensing materials, resulting in a fast response/recovery speed ( $56 \mathrm{~s} / 69 \mathrm{~s}$ ) (Figure 6j). The sensing mechanism is based on the formation of nanostructured $\mathrm{p}-\mathrm{n}$ heterojunctions between hollow $\mathrm{ZnO}$ spheres and $2 \mathrm{D} \mathrm{MoS} 2$ nanosheets, resulting in an electrostatic field formation at their interface, enhancing the sensing performance of the fabricated device compared to the pure counterparts. Here, ultraviolet (UV) light radiation was introduced to further improve acetone response and to significantly reduce the working temperature (down to $30^{\circ} \mathrm{C}$ ). A sensing response of 0.34 towards $100 \mathrm{ppb}$ acetone was achieved at $100{ }^{\circ} \mathrm{C}$, under UV illumination. This excellent sensing response towards acetone is the highest reported so far at such a low operating temperature and is attributed to the synergistic effect of enhanced UV light harvesting (due to the decoration of hierarchical $\mathrm{MoS}_{2}$ nanosheets on the surface of hollow $\mathrm{ZnO}$ spheres) and the unique morphology of the hollow $\mathrm{ZnO} / \mathrm{MoS}_{2}$ $\mathrm{p}-\mathrm{n}$ heterojunctions nanostructure. 


\section{Summary and Outlook}

In conclusion, we reviewed some recent achievements for the development of small, non-invasive, portable, and flexible sensor technologies for highly sensitive, selective measurement of targeted gases for air quality, environmental monitoring, health, and medical applications. Amongst a wide variety of organic and inorganic nanomaterials, metal oxide nanostructured sensors demonstrated the highest sensitivity and selectivity with the lowest LOD. For instance, $\operatorname{In}_{2} \mathrm{O}_{3}$ nanostructured sensors demonstrated high sensitivity and selectivity towards targeted gases. The addition of extraneous metal, such as $\mathrm{Au}, \mathrm{Pt}$ and $\mathrm{Ti}$ via doping or coating significantly improved the sensing performance, however, a relatively high operating temperature $\left(150-400{ }^{\circ} \mathrm{C}\right)$ is still required to activate the sensing material, which hinders their real-world application.

The introduction of nanostructured materials including rGO and graphene, as well as the utilization of other external activation sources including UV and visible light, has dramatically reduced the required operating temperature to low $\left(100^{\circ} \mathrm{C}\right)$ or room temperature $\left(20-30^{\circ} \mathrm{C}\right)$, resulting in a significant energy consumption reduction. This sheds a light on new approaches for nanostructured gas sensor designs via taking advantage of additional energy source, such as light illuminations and/or electromotive forces (voltages) rather than thermal energy to trigger and/or maintain the sensing actuation.

Design, fabrication and sensing mechanism of hybrid films, nanocomposites, doped nanomaterials, nanoscale $\mathrm{p}-\mathrm{n}$ heterojunctions, yolk-shell nanostructures, flexible polymerbased sensors and ultraporous nanofilms were discussed in detail. Despite significant advancements in this area, the major standing challenges include slow response dynamics and lack of selectivity towards targeted gas are still unresolved. New technologies with innovative nanoscale designs could be employed to provide sufficient filtering function to block irrelevant gases and consequently, enhance the sensor's selectivity without compromising its sensitivity.

Nonetheless, optimization of the sensing materials and mechanism for room temperature operating is already becoming an enabling tool for the utilization of nanostructured gas sensors in real-world applications. Materials with porous, ultraporous and hollow sensing nanostructures provides a meaningful and promising avenue to improve the gas sensing performance due to the increased specific surface area and surface to volume ratio. The future development of low temperature sensing technologies is bright, with applications in many aspects of technology, industry, or daily life, providing strong social and financial benefits for addressing the large number of standing fundamental and technological challenges.

Table 1. The key figures of merit of state-of-the-art nanostructured gas sensors.

\begin{tabular}{|c|c|c|c|c|c|c|c|}
\hline Target Gas & Materials & Methods & $\begin{array}{l}\text { Working } \\
\text { Temp. }\left({ }^{\circ} \mathrm{C}\right)\end{array}$ & $\begin{array}{l}\text { Con. } \\
\text { (ppm) }\end{array}$ & Response \# & $\begin{array}{l}\text { Response/Recovery } \\
\text { Time }\end{array}$ & Ref. \\
\hline \multirow{16}{*}{$\mathrm{NO}_{2}$} & $\mathrm{SnS}_{2} / \mathrm{rGO}$ & Hydrothermal & RT & 1 & $6.5^{\mathrm{a}}$ & $75 \mathrm{~s} / \sim 180 \mathrm{~s} *$ & [18] \\
\hline & $\mathrm{rGO} / \mathrm{ZnO}_{1-\mathrm{x}}$ & Hydrothermal & 25 & 0.1 & $4.66^{\mathrm{b}}$ & $1.5 \mathrm{~min} / 2.5 \mathrm{~min}$ & [26] \\
\hline & $\mathrm{ZnO} / \mathrm{rGO}$ & Solvothermal & 110 & 2.5 & 32.11 & $182 \mathrm{~s} / 234 \mathrm{~s}$ & [29] \\
\hline & $\mathrm{SnS}_{2} / \mathrm{rGO}$ & Wet chemistry & 80 & 10 & $0.618^{c}$ & $6 \mathrm{~min} / \sim 53 \mathrm{~min}$ & [30] \\
\hline & $\mathrm{SnS}_{2}$ & Wet chemistry & 120 & 10 & $\sim 35$ & $\sim 170 \mathrm{~s} / \sim 140 \mathrm{~s}$ & [31] \\
\hline & $\mathrm{ZnO} / \mathrm{rGO}$ & $\begin{array}{l}\text { Thermal reduction, } \\
\text { soft solution }\end{array}$ & RT & 5 & 2.5 & $25 \mathrm{~s} / 15 \mathrm{~s}$ & [87] \\
\hline & $\mathrm{g}-\mathrm{C}_{3} \mathrm{~N}_{4} / \mathrm{rGO}$ & $\begin{array}{l}\text { Layer-by-layer } \\
\text { self-assembly }\end{array}$ & RT & 2 & 0.52 & $138 \mathrm{~s} / 318 \mathrm{~s}$ & [88] \\
\hline & $\mathrm{Zn}_{2} \mathrm{SnO}_{4} / \mathrm{rGO}$ & Hydrothermal & 30 & 1 & 0.83 & - & [89] \\
\hline & $\mathrm{S}-\mathrm{rGO} / \mathrm{SnS}_{2}$ & Hydrothermal & RT & 1 & 0.72 & - & [90] \\
\hline & $\mathrm{CdS} / \mathrm{ZnO}$ & Liquid plasma spray & RT & 1 & $30.9^{d}$ & $18.2 \mathrm{~min} />70 \mathrm{~min}$ & [91] \\
\hline & $\mathrm{In} / \mathrm{Ga} / \mathrm{ZnO}$ & RF sputtering & RT & 5 & $0.5^{\mathrm{e}}$ & $-/ 5 \min e$ & [92] \\
\hline & $\mathrm{SnO} / \mathrm{SnO}_{2}$ & Hydrothermal & RT & 0.2 & 1.5 & $57 \mathrm{~s} / 5 \mathrm{~min}$ & [93] \\
\hline & $\mathrm{Si} / \mathrm{WO}_{3}$ & $\begin{array}{l}\text { Chemical etching \& } \\
\text { annealing }\end{array}$ & RT & 5 & 0.92 & $1 \mathrm{~s} / 31 \mathrm{~s}$ & [94] \\
\hline & $\mathrm{NiO} / \mathrm{CuO}$ & Reflux, hydrothermal & RT & 100 & 0.772 & $2 \mathrm{~s} /-$ & [95] \\
\hline & $\alpha-\mathrm{Fe}_{2} \mathrm{O}_{3} / \mathrm{PANI}$ & Polymerization & RT & 20 & 228 & $2.3 \mathrm{~min} / 2.4 \mathrm{~min}$ & [96] \\
\hline & $\mathrm{CuPcTS} / \mathrm{SnO}_{2}$ & Spin coating & 50 & 1 & 2399 & $5 \mathrm{~min} / 10 \mathrm{~min}$ & [97] \\
\hline
\end{tabular}


Table 1. Cont.

\begin{tabular}{|c|c|c|c|c|c|c|c|}
\hline Target Gas & Materials & Methods & $\begin{array}{l}\text { Working } \\
\text { Temp. }\left({ }^{\circ} \mathrm{C}\right)\end{array}$ & $\begin{array}{l}\text { Con. } \\
\text { (ppm) }\end{array}$ & Response \# & $\begin{array}{l}\text { Response/Recovery } \\
\text { Time }\end{array}$ & Ref. \\
\hline \multirow{8}{*}{$\mathrm{SO}_{2}$} & $\mathrm{Ni}_{3} \mathrm{BTC}_{2} / \mathrm{OH}-\mathrm{SWNTs}$ & Solvothermal & RT & 15 & $0.85 *$ & $5.59 \mathrm{~s} / 11.04 \mathrm{~s}$ & [33] \\
\hline & $\mathrm{Cu}: \mathrm{SnO}_{2}$ & \multirow{2}{*}{$\begin{array}{l}\text { Precipitation } \\
\text { Layer-by-layer } \\
\text { self-assembly }\end{array}$} & 250 & 6 & 90.51 & $4.5 \mathrm{~min} / 15 \mathrm{~min}$ & {$[34]$} \\
\hline & $\mathrm{g}-\mathrm{C}_{3} \mathrm{~N}_{4} / \mathrm{rGO}$ & & RT & 20 & $0.09^{\mathrm{f}}$ & $140 \mathrm{~s}^{\mathrm{f}} / 130 \mathrm{~s}^{\mathrm{f}}$ & [88] \\
\hline & $\mathrm{rGO} / \mathrm{WO}_{3}$ & $\begin{array}{l}\text { Metal organic } \\
\text { decomposition }\end{array}$ & 25 & 0.3 & 0.027 & $66 \mathrm{~s} / 298 \mathrm{~s}$ & [98] \\
\hline & $\mathrm{Au} / \mathrm{SnO}_{2-\mathrm{X}}$ & Hydrothermal & 200 & 20 & 0.904 & $34 \mathrm{~s} / 14 \mathrm{~s}$ & [99] \\
\hline & PANI & Template-free & RT & 5 & 0.045 & $185 \mathrm{~s} /<200 \mathrm{~s}$ & [100] \\
\hline & $\mathrm{Ru} / \mathrm{Al}_{2} \mathrm{O}_{3} / \mathrm{ZnO}$ & $\begin{array}{l}\text { Hydrothermal \& inkjet } \\
\text { printing }\end{array}$ & 350 & 25 & 0.2 & $\sim 1 \mathrm{~min} / \sim 6 \min$ & [101] \\
\hline & $\mathrm{NH}_{4}{ }^{+} \mathrm{ZSM}-5$ (23) & Ion exchange & RT & 4200 & 0.85 & $63 \mathrm{~min} / 3 \mathrm{~min}$ & [102] \\
\hline \multirow{5}{*}{$\mathrm{CO}_{2}$} & $\mathrm{CeO}_{2}$ & Solvothermal & 100 & 2400 & 2.9 & $2.58 \mathrm{~min} / 4.08 \mathrm{~min}$ & [48] \\
\hline & $\mathrm{Ag} / \mathrm{CuO} / \mathrm{BaTiO}_{3}$ & Hydrothermal & 120 & 700 & 0.4 & $3 \mathrm{~s} / 8 \mathrm{~s}$ & [49] \\
\hline & Graphene PEI/PEG & $\begin{array}{l}\text { CVD \& e-beam } \\
\text { evaporation }\end{array}$ & RT & 5000 & $0.3^{g}$ & $\begin{array}{l}\text { "several tens } \\
\text { of seconds" }\end{array}$ & {$[52]$} \\
\hline & SWCNTs/Q4VP-VBAm & Spray coating & 21 & 20000 & $0.25^{*}$ & $<1000 \mathrm{~s} * / \sim 3000 \mathrm{~s}$ & [53] \\
\hline & $\mathrm{Pd} / \mathrm{La}_{2} \mathrm{O}_{3}$ & Spray pyrolysis & 250 & 500 & 2.57 & $105 \mathrm{~s} / 145 \mathrm{~s}$ & [103] \\
\hline \multirow{6}{*}{$\mathrm{NH}_{3}$} & PANI & Polymerization & 24 & 0.0025 & 0.03 & - & [65] \\
\hline & $\mathrm{CuBr}$ & FSP & RT & 5 & 276 & $2.2 \mathrm{~min} / 50 \mathrm{~s}$ & [66] \\
\hline & PET/MWCNTs/PANI & EDA modification & $\sim 15-18$ & 50 & 1.17 & $47 \mathrm{~s} /-$ & [67] \\
\hline & $\mathrm{SnO}_{2} / \mathrm{PANI}$ & $\begin{array}{l}\text { Hydrothermal, } \\
\text { polymerization }\end{array}$ & 28 & 100 & 28.8 & $125 \mathrm{~s} / 167 \mathrm{~s}$ & [68] \\
\hline & S-rGO/SnS 2 & Hydrothermal & $\mathrm{RT}$ & 20 & 0.45 & - & [90] \\
\hline & SWCNTs & Hydrothermal & RT & 1.5 & 0.032 & $10 \mathrm{~min} /-\mathrm{h}$ & [104] \\
\hline \multirow{6}{*}{$\mathrm{C}_{5} \mathrm{H}_{8}$} & Ti:ZnO & FSP & 325 & 0.02 & 0.26 & $\sim 1 \mathrm{~min} / \sim 5 \mathrm{~min}$ & [70] \\
\hline & $\mathrm{Au} / \mathrm{ZnO}$ & $\begin{array}{l}\text { Solvothermal, } \\
\text { annealing }\end{array}$ & 350 & 1 & $\sim 1$ & $\sim 2 \min * /-$ & {$[74]$} \\
\hline & $\mathrm{In}_{2} \mathrm{O}_{3}$ & Hydrothermal & 190 & 5 & 0.75 & $53 \mathrm{~s} / 299 \mathrm{~s}$ & [75] \\
\hline & $\mathrm{Pt}: \mathrm{SnO}_{2}$ & FSP & 400 & 0.5 & $\sim 0.75$ & $10 \mathrm{~s} / 20 \mathrm{~s} *$ & {$[76]$} \\
\hline & $\mathrm{Pt} / \mathrm{In}_{2} \mathrm{O}_{3}$ & Hydrothermal & 200 & 5 & 0.99 & $124 \mathrm{~s} / 204 \mathrm{~s}$ & [105] \\
\hline & $\mathrm{Cr}_{2} \mathrm{O}_{3}: \mathrm{In}_{2} \mathrm{O}_{3}$ & Hydrothermal & 240 & 0.5 & 0.95 & $135 \mathrm{~s} / 830 \mathrm{~s}$ & [106] \\
\hline \multirow{8}{*}{$\mathrm{C}_{3} \mathrm{H}_{6} \mathrm{O}$} & $\mathrm{ZnO} / \mathrm{CuO}$ & \multirow{8}{*}{$\begin{array}{l}\text { Thermal oxidation } \\
\text { Photochemical } \\
\text { activation } \\
\text { Precipitation } \\
\text { Hydrothermal } \\
\text { Hydrothermal } \\
\text { Hydrothermal } \\
\text { Hydrothermal } \\
\text { Pyrolysis, sonication }\end{array}$} & 200 & 1 & 10.14 & - & [46] \\
\hline & $\mathrm{In} / \mathrm{Ga} / \mathrm{ZnO}$ & & RT & 750 & $0.27^{\mathrm{i}}$ & $37 \mathrm{~s} / 53 \mathrm{~s}$ & [81] \\
\hline & $\mathrm{Au} / \mathrm{ZnO}$ & & 172 & 100 & 0.98 & $1 \mathrm{~s} / 20 \mathrm{~s}$ & [82] \\
\hline & $\mathrm{WO}_{3}$ & & 320 & 0.25 & 0.97 & $5 \mathrm{~s} / 5 \mathrm{~s}$ & [83] \\
\hline & $\mathrm{HZnO} / \mathrm{MoS}_{2}$ & & 30 & 50 & $\sim 0.25^{\mathrm{j}}$ & $19 \mathrm{~s} / 97 \mathrm{~s}$ & [84] \\
\hline & $\mathrm{Co}_{3} \mathrm{O}_{4} / \mathrm{SnO}_{2}$ & & 220 & 50 & 0.92 & $12 \mathrm{~s} / 18 \mathrm{~s}$ & [85] \\
\hline & $\mathrm{Co}_{3} \mathrm{O}_{4} / \mathrm{CoWO}_{4}$ & & 255 & 20 & 8.9 & $22 \mathrm{~s} / 12 \mathrm{~s}$ & [86] \\
\hline & $\mathrm{Au} / \mathrm{ZnO}$ & & 365 & 100 & $\sim 1$ & $5 s /-$ & [107] \\
\hline
\end{tabular}

\# The mathematic expression of sensing response $(S)$ varies in some literatures, herein, it is converted correspondingly via the unified formula of $S=\frac{\left|R_{g}-R_{a}\right|}{R_{a}}$, or $S=\frac{\left|I_{0}-I\right|}{I}$, where $I_{0}$ and $I$ are the currents detected before and after targeted gas exposure respectively. * Estimated/calculated from the graph, data is unavailable; ${ }^{\text {a }}$ Assisted under Red light $\left(650 \mathrm{~nm}, 1 \mathrm{~mW} \cdot \mathrm{cm}^{-2}\right)$ and bias $(5-15 \mathrm{~V}) ;{ }^{\mathrm{b}}$ Assisted under white-light illumination with a light density of $0.15 \mathrm{~W} \cdot \mathrm{cm}^{-2} ;{ }^{c}$ Assisted by applying a bias of $1 \mathrm{~V} ;{ }^{\mathrm{d}}$ Assisted under Green light $\left(510 \mathrm{~nm}, 0.05 \mathrm{~W} \cdot \mathrm{cm}^{-2}\right)$; ${ }^{\mathrm{e}}$ Assisted under blue light $\left(450 \mathrm{~nm}, 1 \mathrm{~mW} \cdot \mathrm{cm}^{-2}\right)$; ${ }^{\mathrm{f}}$ Assisted under UV light illumination and the bias of $3 \mathrm{~V}$; $\mathrm{g}$ Assisted by applying a bias of $0.1 \mathrm{~V} ;{ }^{\mathrm{h}}$ A local heater or a UV LED has to be used for the full recovery of the sensor after each sensing cycle; ${ }^{i}$ Assisted under UV light $\left(390 \mathrm{~nm}, 30 \mathrm{~mW} \cdot \mathrm{cm}^{-2}\right) ;{ }^{j}$ Assisted under UV light $\left(375 \mathrm{~nm}, 50 \mu W \cdot \mathrm{cm}^{-2}\right)$.

Author Contributions: The original draft preparation was done by X.C and N.N. The table was prepared by X.C. The figures were prepared by X.C and N.N. Conceptualization, design and supervision were done by N.N. and D.B. The review, validation and final editing of the manuscript was carried out by X.C, M.L., D.B. and N.N. All authors have read and agreed to the published version of the manuscript.

Funding: This research received no external funding.

Informed Consent Statement: Not applicable.

Data Availability Statement: Not applicable.

Conflicts of Interest: The authors declare no conflict of interest. 


\section{References}

1. Rim-Rukeh, A. An Assessment of the Contribution of Municipal Solid Waste Dump Sites Fire to Atmospheric Pollution. Open J. Air Pollut. 2014, 3, 53-60. [CrossRef]

2. Morillas, H.; Maguregui, M.; Gallego-Cartagena, E.; Marcaida, I.; Carral, N.; Madariaga, J.M. The influence of marine environment on the conservation state of Built Heritage: An overview study. Sci. Total Environ. 2020, 745, 140899. [CrossRef] [PubMed]

3. Kumar, S. Acid rain-the major cause of pollution: Its causes, effects. Int. J. Appl. Chem 2017, 13, 53-58.

4. Wu, R.; Xie, S. Spatial Distribution of Secondary Organic Aerosol Formation Potential in China Derived from Speciated Anthropogenic Volatile Organic Compound Emissions. Environ. Sci. Technol. 2018, 52, 8146-8156. [CrossRef]

5. Raza, W.; Saeed, S.; Saulat, H.; Gul, H.; Sarfraz, M.; Sonne, C.; Sohn, Z.H.; Brown, R.J.C.; Kim, K.-H. A review on the deteriorating situation of smog and its preventive measures in Pakistan. J. Clean. Prod. 2021, 279, 123676. [CrossRef]

6. Nie, E.; Zheng, G.; Shao, Z.; Yang, J.; Chen, T. Emission characteristics and health risk assessment of volatile organic compounds produced during municipal solid waste composting. Waste Manage. 2018, 79, 188-195. [CrossRef]

7. WHO. Burden of Disease from the Joint Effects of Household and Ambient Air Pollution for 2016; WHO: Geneva, Switzerland, 2018.

8. Lelieveld, J.; Evans, J.S.; Fnais, M.; Giannadaki, D.; Pozzer, A. The contribution of outdoor air pollution sources to premature mortality on a global scale. Nature 2015, 525, 367-371. [CrossRef]

9. Nasiri, N.; Clarke, C. Nanostructured Chemiresistive Gas Sensors for Medical Applications. Sensors 2019, 19, 462. [CrossRef] [PubMed]

10. Tricoli, A.; Nasiri, N.; De, S. Wearable and Miniaturized Sensor Technologies for Personalized and Preventive Medicine. Adv. Funct. Mater. 2017, 27, 1605271. [CrossRef]

11. Kharitonov, S.A.; Barnes, P.J. Biomarkers of some pulmonary diseases in exhaled breath. Biomarkers 2002, 7, 1-32. [CrossRef]

12. Nasiri, N. Introductory Chapter: Wearable Technologies for Healthcare Monitoring. In Wearable Devices: The Big Wave of Innovation; IntechOpen: London, UK, 2019. [CrossRef]

13. Adir, O.; Poley, M.; Chen, G.; Froim, S.; Krinsky, N.; Shklover, J.; Shainsky-Roitman, J.; Lammers, T.; Schroeder, A. Integrating Artificial Intelligence and Nanotechnology for Precision Cancer Medicine. Adv. Mater. 2020, 32, 1901989. [CrossRef] [PubMed]

14. Sayago, I.; Aleixandre, M.; Santos, J.P. Development of Tin Oxide-Based Nanosensors for Electronic Nose Environmental Applications. Biosensors 2019, 9, 21. [CrossRef] [PubMed]

15. Nasiri, N.; Clarke, C. Nanostructured Gas Sensors for Medical and Health Applications: Low to High Dimensional Materials. Biosensors 2019, 9, 43. [CrossRef] [PubMed]

16. Xie, X.; Semanjski, I.; Gautama, S.; Tsiligianni, E.; Deligiannis, N.; Rajan, R.; Pasveer, F.; Philips, W. A Review of Urban Air Pollution Monitoring and Exposure Assessment Methods. ISPRS Int. J. Geoinf. 2017, 6, 389. [CrossRef]

17. Yi, W.; Lo, K.; Mak, T.; Leung, K.; Leung, Y.; Meng, M. A Survey of Wireless Sensor Network Based Air Pollution Monitoring Systems. Sensors 2015, 15, 31392-31427. [CrossRef]

18. Huang, Y.; Jiao, W.; Chu, Z.; Ding, G.; Yan, M.; Zhong, X.; Wang, R. Ultrasensitive room temperature ppb-level $\mathrm{NO}_{2}$ gas sensors based on $\mathrm{SnS}_{2} / \mathrm{rGO}$ nanohybrids with P-N transition and optoelectronic visible light enhancement performance. J. Mater. Chem. C 2019, 7, 8616-8625. [CrossRef]

19. Chen, T.-M.; Kuschner, W.G.; Gokhale, J.; Shofer, S. Outdoor Air Pollution: Nitrogen Dioxide, Sulfur Dioxide, and Carbon Monoxide Health Effects. Am. J. Med. Sci. 2007, 333, 249-256. [CrossRef]

20. WHO. Air Quality Guidelines for Particulate Matter, Ozone, Nitrogen Dioxide and Sulfur Dioxide: Global Update 2005; WHO: Geneva, Switzerland, 2006.

21. Richter, A.; Burrows, J.P.; Nüß, H.; Granier, C.; Niemeier, U. Increase in tropospheric nitrogen dioxide over China observed from space. Nature 2005, 437, 129-132. [CrossRef]

22. Lerdau, M.T.; Munger, J.W. The $\mathrm{NO}_{2}$ flux conundrum. Science 2000, 289, 2000. [CrossRef]

23. Shukla, J.B.; Sundar, S.; Shivangi; Naresh, R. Modeling and analysis of the acid rain formation due to precipitation and its effect on plant species. Nat. Resour. Model. 2013, 26, 53-65. [CrossRef]

24. Lyimo, T.J. Microbial and nutrient pollution in the coastal bathing waters of Dar es Salaam. Aquat. Conserv. 2009, 19, S27-S37. [CrossRef]

25. Korotchenkov, G.S. Handbook of Gas Sensor Materials; Spinger: New York, NY, USA, 2013; Volume 1.

26. Geng, X.; Lu, P.; Zhang, C.; Lahem, D.; Olivier, M.-G.; Debliquy, M. Room-temperature $\mathrm{NO}_{2}$ gas sensors based on rGO@ZnO composites: Experiments and molecular dynamics simulation. Sens. Actuators B Chem. 2019, 282, 690-702. [CrossRef]

27. Nasiri, N.; Bo, R.H.; Wang, F.; Fu, L.; Tricoli, A. Ultraporous Electron-Depleted ZnO Nanoparticle Networks for Highly Sensitive Portable Visible-Blind UV Photodetectors. Adv. Mater. 2015, 27, 4336-4343. [CrossRef]

28. Nasiri, N.; Bo, R.; Hung, T.F.; Roy, V.A.L.; Fu, L.; Tricoli, A. Tunable Band-Selective UV-Photodetectors by 3D Self-Assembly of Heterogeneous Nanoparticle Networks. Adv. Funct. Mater. 2016, 26, 7359-7366. [CrossRef]

29. Cao, P.; Cai, Y.; Pawar, D.; Navale, S.T.; Rao, C.N.; Han, S.; Xu, W.; Fang, M.; Liu, X.; Zeng, Y.; et al. Down to ppb level NO 2 detection by $\mathrm{ZnO} / \mathrm{rGO}$ heterojunction based chemiresistive sensors. Chem. Eng. J. 2020, 401, 125491. [CrossRef]

30. Shafiei, M.; Bradford, J.; Khan, H.; Piloto, C.; Wlodarski, W.; Li, Y.X.; Motta, N. Low-operating temperature $\mathrm{NO}_{2}$ gas sensors based on hybrid two-dimensional $\mathrm{SnS}_{2}$-reduced graphene oxide. Appl. Surf. Sci. 2018, 462, 330-336. [CrossRef] 
31. Ou, J.Z.; Ge, W.; Carey, B.; Daeneke, T.; Rotbart, A.; Shan, W.; Wang, Y.; Fu, Z.; Chrimes, A.F.; Wlodarski, W.; et al. PhysisorptionBased Charge Transfer in Two-Dimensional $\mathrm{SnS}_{2}$ for Selective and Reversible $\mathrm{NO}_{2}$ Gas Sensing. Acs Nano 2015, 9, 10313-10323. [CrossRef]

32. Das, S.; Chakraborty, S.; Parkash, O.; Kumar, D.; Bandyopadhyay, S.; Samudrala, S.K.; Sen, A.; Maiti, H.S. Vanadium doped tin dioxide as a novel sulfur dioxide sensor. Talanta 2008, 75, 385-389. [CrossRef]

33. Ingle, N.; Mane, S.; Sayyad, P.; Bodkhe, G.; Al-Gahouari, T.; Mahadik, M.; Shirsat, S.; Shirsat, M.D. Sulfur Dioxide (SO 2 ) Detection Using Composite of Nickel Benzene Carboxylic $\left(\mathrm{Ni}_{3} \mathrm{BTC}_{2}\right)$ and $\mathrm{OH}$-Functionalized Single Walled Carbon Nanotubes (OH-SWNTs). Front. Mater. Sci. 2020, 7. [CrossRef]

34. Zhao, C.H.; Gong, H.M.; Niu, G.Q.; Wang, F. Ultrasensitive $\mathrm{SO}_{2}$ sensor for sub-ppm detection using Cu-doped $\mathrm{SnO} \mathrm{O}_{2}$ nanosheet arrays directly grown on chip. Sens. Actuators B Chem. 2020, 324. [CrossRef]

35. Dey, A. Semiconductor metal oxide gas sensors: A review. Mater. Sci. Eng. B 2018, 229, 206-217. [CrossRef]

36. Wang, X.; Yao, F.; Xu, P.; Li, M.; Yu, H.; Li, X. Quantitative Structure-Activity Relationship of Nanowire Adsorption to $\mathrm{SO}_{2}$ Revealed by In Situ TEM Technique. Nano Lett. 2021, 21, 1679-1687. [CrossRef] [PubMed]

37. Zhai, Y.; Chuang, S.S.C. The Nature of Adsorbed Carbon Dioxide on Immobilized Amines during Carbon Dioxide Capture from Air and Simulated Flue Gas. Energy Technol. 2017, 5, 510-519. [CrossRef]

38. Ritchie, H.; Roser, M. $\mathrm{CO}_{2}$ and Greenhouse Gas Emission. Available online: https://ourworldindata.org/co2-and-othergreenhouse-gas-emissions (accessed on 13 May 2021).

39. Lacis, A.A.; Schmidt, G.A.; Rind, D.; Ruedy, R.A. Atmospheric $\mathrm{CO}_{2}$ : Principal Control Knob Governing Earth's Temperature. Science 2010, 330, 356-359. [CrossRef] [PubMed]

40. Solomon, S.; Plattner, G.-K.; Knutti, R.; Friedlingstein, P. Irreversible climate change due to carbon dioxide emissions. Proc. Natl. Acad. Sci. USA 2009, 106, 1704-1709. [CrossRef]

41. Ramalho, O.; Wyart, G.; Mandin, C.; Blondeau, P.; Cabanes, P.-A.; Leclerc, N.; Mullot, J.-U.; Boulanger, G.; Redaelli, M. Association of carbon dioxide with indoor air pollutants and exceedance of health guideline values. Build Environ. 2015, 93, 115-124. [CrossRef]

42. Jacobson, T.A.; Kler, J.S.; Hernke, M.T.; Braun, R.K.; Meyer, K.C.; Funk, W.E. Direct human health risks of increased atmospheric carbon dioxide. Nat. Sustain. 2019, 2, 691-701. [CrossRef]

43. Griffiths, S.; Sovacool, B.K. Rethinking the future low-carbon city: Carbon neutrality, green design, and sustainability tensions in the making of Masdar City. Energy Res. Soc. Sci. 2020, 62, 101368. [CrossRef]

44. Molina, A.; Escobar-Barrios, V.; Oliva, J. A review on hybrid and flexible $\mathrm{CO}_{2}$ gas sensors. Synth. Met. 2020, 270 , 116602 [CrossRef]

45. Jeong, H.-M.; Kim, J.-H.; Jeong, S.-Y.; Kwak, C.-H.; Lee, J.-H. $\mathrm{Co}_{3} \mathrm{O}_{4}-\mathrm{SnO}_{2}$ Hollow Heteronanostructures: Facile Control of Gas Selectivity by Compositional Tuning of Sensing Materials via Galvanic Replacement. ACS Appl. Mater. Interfaces 2016, 8, 7877-7883. [CrossRef]

46. Lee, J.E.; Lim, C.K.; Park, H.J.; Song, H.; Choi, S.-Y.; Lee, D.-S. ZnO-CuO Core-Hollow Cube Nanostructures for Highly Sensitive Acetone Gas Sensors at the ppb Level. ACS Appl. Mater. Interfaces 2020, 12, 35688-35697. [CrossRef] [PubMed]

47. Li, X.; Lu, D.; Shao, C.; Lu, G.; Li, X.; Liu, Y. Hollow $\mathrm{CuFe}_{2} \mathrm{O}_{4} / \alpha-\mathrm{Fe}_{2} \mathrm{O}_{3}$ composite with ultrathin porous shell for acetone detection at ppb levels. Sens. Actuators B Chem. 2018, 258, 436-446. [CrossRef]

48. Zito, C.A.; Perfecto, T.M.; Dippel, A.-C.; Volanti, D.P.; Koziej, D. Low-Temperature Carbon Dioxide Gas Sensor Based on Yolk-Shell Ceria Nanospheres. ACS Appl. Mater. Interfaces 2020, 12, 17745-17751. [CrossRef] [PubMed]

49. Joshi, S.; Ippolito, S.J.; Periasamy, S.; Sabri, Y.M.; Sunkara, M.V. Efficient Heterostructures of $\mathrm{Ag} @ \mathrm{CuO} / \mathrm{BaTiO} 3$ for LowTemperature $\mathrm{CO}_{2}$ Gas Detection: Assessing the Role of Nanointerfaces during Sensing by Operando DRIFTS Technique. ACS Appl. Mater. Interfaces 2017, 9, 27014-27026. [CrossRef] [PubMed]

50. Lacerda, L.H.S.; de Lazaro, S.R. A theoretical investigation of the Zn-doping influence on structural and electronic properties of BaTiO3. Solid State Ion. 2016, 297, 36-42. [CrossRef]

51. Lee, S.; Bock, J.A.; Trolier-Mckinstry, S.; Randall, C.A. Ferroelectric-thermoelectricity and Mott transition of ferroelectric oxides with high electronic conductivity. J. Eur. Ceram. 2012, 32, 3971-3988. [CrossRef]

52. Son, M.; Pak, Y.; Chee, S.-S.; Auxilia, F.M.; Kim, K.; Lee, B.-K.; Lee, S.; Kang, S.K.; Lee, C.; Lee, J.S.; et al. Charge transfer in graphene/polymer interfaces for $\mathrm{CO}_{2}$ detection. Nano Res. 2018, 11, 3529-3536. [CrossRef]

53. Yoon, B.; Choi, S.-J.; Swager, T.M.; Walsh, G.F. Switchable Single-Walled Carbon Nanotube-Polymer Composites for $\mathrm{CO}_{2}$ Sensing ACS Appl. Mater. Interfaces 2018, 10, 33373-33379. [CrossRef]

54. Righettoni, M.; Amann, A.; Pratsinis, S.E. Breath analysis by nanostructured metal oxides as chemo-resistive gas sensors. Mater. Today 2015, 18, 163-171. [CrossRef]

55. Pereira, J.; Porto-Figueira, P.; Cavaco, C.; Taunk, K.; Rapole, S.; Dhakne, R.; Nagarajaram, H.; Câmara, J. Breath Analysis as a Potential and Non-Invasive Frontier in Disease Diagnosis: An Overview. Metabolites 2015, 5, 3-55. [CrossRef]

56. Xu, R.; Tian, H.; Pan, S.; Prior, S.A.; Feng, Y.; Batchelor, W.D.; Chen, J.; Yang, J. Global ammonia emissions from synthetic nitrogen fertilizer applications in agricultural systems: Empirical and process-based estimates and uncertainty. Glob. Chang. Biol. 2019, 25, 314-326. [CrossRef]

57. Ghavam, S.; Vahdati, M.; Wilson, I.A.G.; Styring, P. Sustainable Ammonia Production Processes. Front. Energy Res. $2021,9$. [CrossRef] 
58. Liu, G.K.; Zhu, L.J.; Yu, Y.M.; Qiu, M.; Gao, H.J.; Chen, D.Y. $\mathrm{WO}_{3}$ nanoplates for sensitive and selective detections of both acetone and $\mathrm{NH}_{3}$ gases at different operating temperatures. J. Alloys Compd. 2021, 858. [CrossRef]

59. Saidi, T.; Zaim, O.; Moufid, M.; El Bari, N.; Ionescu, R.; Bouchikhi, B. Exhaled breath analysis using electronic nose and gas chromatography-mass spectrometry for non-invasive diagnosis of chronic kidney disease, diabetes mellitus and healthy subjects. Sens. Actuators B Chem. 2018, 257, 178-188. [CrossRef]

60. Mitrayana, M.; Ma'arif, M.A.; Wasono, M.A.J.; Satriawan, M.; Ikhsan, M.R. Application of the $\mathrm{CO}_{2}$ laser photoacoustic spectroscopy in detecting ammonia gas $\left(\mathrm{NH}_{3}\right)$ in liver disease patients breath. Key Eng. Mater. 2020, 840, 399-405. [CrossRef]

61. Yang, T.; Jiang, X.; Zhong, Y.; Zhao, X.; Lin, S.; Li, J.; Li, X.; Xu, J.; Li, Z.; Zhu, H. A Wearable and Highly Sensitive Graphene Strain Sensor for Precise Home-Based Pulse Wave Monitoring. ACS Sens. 2017, 2, 967-974. [CrossRef]

62. Subbiah, D.K.; Mani, G.K.; Babu, K.J.; Das, A.; Rayappan, J.B.B. Nanostructured ZnO on cotton fabrics A novel flexible gas sensor \& UV filter. J. Clean. Prod. 2018, 194, 372-382. [CrossRef]

63. Kassem, O.; Saadaoui, M.; Rieu, M.; Viricelle, J.-P. A novel approach to a fully inkjet printed $\mathrm{SnO}_{2}$-based gas sensor on a flexible foil. J. Mater. Chem. C 2019, 7, 12343-12353. [CrossRef]

64. Yu, Z.; Tang, Y.; Cai, G.; Ren, R.; Tang, D. Paper Electrode-Based Flexible Pressure Sensor for Point-of-Care Immunoassay with Digital Multimeter. Anal. Chem. 2019, 91, 1222-1226. [CrossRef] [PubMed]

65. Cai, J.; Zhang, C.; Khan, A.; Liang, C.; Li, W.-D. Highly transparent and flexible polyaniline mesh sensor for chemiresistive sensing of ammonia gas. RSC Adv. 2018, 8, 5312-5320. [CrossRef]

66. Güntner, A.T.; Wied, M.; Pineau, N.J.; Pratsinis, S.E. Rapid and Selective $\mathrm{NH}_{3}$ Sensing by Porous CuBr. Adv. Sci. 2020, 7, 1903390. [CrossRef]

67. Ma, J.; Fan, H.; Li, Z.; Jia, Y.; Yadav, A.K.; Dong, G.; Wang, W.; Dong, W.; Wang, S. Multi-walled carbon nanotubes/polyaniline on the ethylenediamine modified polyethylene terephthalate fibers for a flexible room temperature ammonia gas sensor with high responses. Sens. Actuators B Chem. 2021, 334, 129677. [CrossRef]

68. Li, S.; Liu, A.; Yang, Z.; He, J.; Wang, J.; Liu, F.; Lu, H.; Yan, X.; Sun, P.; Liang, X.; et al. Room temperature gas sensor based on tin dioxide@polyaniline nanocomposite assembled on flexible substrate: Ppb-level detection of $\mathrm{NH}_{3}$. Sens. Actuators B Chem. 2019, 299, 126970. [CrossRef]

69. Karl, T.; Prazeller, P.; Mayr, D.; Jordan, A.; Rieder, J.; Fall, R.; Lindinger, W. Human breath isoprene and its relation to blood cholesterol levels: New measurements and modeling. J. Appl. Physiol. 2001, 91, 762-770. [CrossRef]

70. Güntner, A.T.; Pineau, N.J.; Chie, D.; Krumeich, F.; Pratsinis, S.E. Selective sensing of isoprene by Ti-doped ZnO for breath diagnostics. J. Mater. Chem. B 2016, 4, 5358-5366. [CrossRef] [PubMed]

71. Fuchs, D.; Jamnig, H.; Heininger, P.; Klieber, M.; Schroecksnadel, S.; Fiegl, M.; Hackl, M.; Denz, H.; Amann, A. Decline of exhaled isoprene in lung cancer patients correlates with immune activation. J. Breath Res. 2012, 6. [CrossRef] [PubMed]

72. Bajtarevic, A.; Ager, C.; Pienz, M.; Klieber, M.; Schwarz, K.; Ligor, M.; Ligor, T.; Filipiak, W.; Denz, H.; Fiegl, M.; et al. Noninvasive detection of lung cancer by analysis of exhaled breath. BMC Cancer 2009, 9, 348. [CrossRef] [PubMed]

73. Alkhouri, N.; Singh, T.; Alsabbagh, E.; Guirguis, J.; Chami, T.; Hanouneh, I.; Grove, D.; Lopez, R.; Dweik, R. Isoprene in the Exhaled Breath is a Novel Biomarker for Advanced Fibrosis in Patients with Chronic Liver Disease: A Pilot Study. Clin. Transl. Gastroenterol. 2015, 6. [CrossRef] [PubMed]

74. Saito, N.; Haneda, H.; Watanabe, K.; Shimanoe, K.; Sakaguchi, I. Highly sensitive isoprene gas sensor using Au-loaded pyramidshaped ZnO particles. Sens. Actuators B Chem. 2021, 326, 128999. [CrossRef]

75. Han, B.; Wang, J.; Yang, W.; Chen, X.; Wang, H.; Chen, J.; Zhang, C.; Sun, J.; Wei, X. Hydrothermal synthesis of flower-like In ${ }_{2} \mathrm{O}_{3}$ as a chemiresistive isoprene sensor for breath analysis. Sens. Actuators B Chem. 2020, 309, 127788. [CrossRef]

76. Van Den Broek, J.; Güntner, A.T.; Pratsinis, S.E. Highly Selective and Rapid Breath Isoprene Sensing Enabled by Activated Alumina Filter. ACS Sens. 2018, 3, 677-683. [CrossRef] [PubMed]

77. Wang, Z.N.; Wang, C.J. Is breath acetone a biomarker of diabetes? A historical review on breath acetone measurements. J. Breath Res. 2013, 7. [CrossRef]

78. Deng, C.; Zhang, J.; Yu, X.; Zhang, W.; Zhang, X. Determination of acetone in human breath by gas chromatography-mass spectrometry and solid-phase microextraction with on-fiber derivatization. J. Chromatogr. B Biomed. Appl. 2004, 810, 269-275. [CrossRef]

79. Diskin, A.M.; Spanel, P.; Smith, D. Time variation of ammonia, acetone, isoprene and ethanol in breath: A quantitative SIFT-MS study over 30 days. Physiol. Meas. 2003, 24, 107-119. [CrossRef]

80. WHO. World Health Statistics 2016: Monitoring Health for the Sustainable Development Goals (SDGs); WHO: Geneva, Switzerland, 2016; ISBN 9789240695696.

81. Jaisutti, R.; Kim, J.; Park, S.K.; Kim, Y.-H. Low-Temperature Photochemically Activated Amorphous Indium-Gallium-Zinc Oxide for Highly Stable Room-Temperature Gas Sensors. ACS Appl. Mater. Interfaces 2016, 8, 20192-20199. [CrossRef]

82. Yang, M.; Zhang, S.; Qu, F.; Gong, S.; Wang, C.; Qiu, L.; Yang, M.; Cheng, W. High performance acetone sensor based on ZnO nanorods modified by Au nanoparticles. J. Alloys Compd. 2019, 797, 246-252. [CrossRef]

83. Lu, J.; Xu, C.; Cheng, L.; Jia, N.; Huang, J.; Li, C. Acetone sensor based on $\mathrm{WO}_{3}$ nanocrystallines with oxygen defects for low concentration detection. Mater. Sci. Semicond. Process. 2019, 101, 214-222. [CrossRef]

84. Chang, X.; Qiao, X.; Li, K.; Wang, P.; Xiong, Y.; Li, X.; Xia, F.; Xue, Q. UV assisted ppb-level acetone detection based on hollow $\mathrm{ZnO} / \mathrm{MoS}_{2}$ nanosheets core/shell heterostructures at low temperature. Sens. Actuators B Chem. 2020, 317, 128208. [CrossRef] 
85. Xu, Y.; Zheng, L.; Yang, C.; Liu, X.; Zhang, J. Highly sensitive and selective electronic sensor based on $\mathrm{Co}^{2}$ catalyzed $\mathrm{SnO}{ }_{2}$ nanospheres for acetone detection. Sens. Actuators B Chem. 2020, 304, 127237. [CrossRef]

86. Qu, F.; Zhang, N.; Zhang, S.; Zhao, R.; Yao, D.; Ruan, S.; Yang, M. Construction of $\mathrm{Co}_{3} \mathrm{O}_{4} /$ CoWO $\mathrm{C}_{4}$ core-shell urchin-like microspheres through ion-exchange method for high-performance acetone gas sensing performance. Sens. Actuators $B$ Chem. 2020, 309, 127711. [CrossRef]

87. Liu, Z.; Yu, L.; Guo, F.; Liu, S.; Qi, L.; Shan, M.; Fan, X. Facial development of high performance room temperature $\mathrm{NO}_{2}$ gas sensors based on ZnO nanowalls decorated rGO nanosheets. Appl. Surf. Sci. 2017, 423, 721-727. [CrossRef]

88. Chen, A.; Liu, R.; Peng, X.; Chen, Q.; Wu, J. 2D Hybrid Nanomaterials for Selective Detection of $\mathrm{NO}_{2}$ and $\mathrm{SO}_{2} \mathrm{Using}_{\text {"Light On }}$ and Off" Strategy. ACS Appl. Mater. Interfaces 2017, 9, 37191-37200. [CrossRef] [PubMed]

89. Wang, Z.; Sackmann, A.; Gao, S.; Weimar, U.; Lu, G.; Liu, S.; Zhang, T.; Barsan, N. Study on highly selective sensing behavior of ppb-level oxidizing gas sensors based on $\mathrm{Zn}_{2} \mathrm{SnO}_{4}$ nanoparticles immobilized on reduced graphene oxide under humidity conditions. Sens. Actuators B Chem. 2019, 285, 590-600. [CrossRef]

90. Huang, Y.; Jiao, W.; Chu, Z.; Wang, S.; Chen, L.; Nie, X.; Wang, R.; He, X. High Sensitivity, Humidity-Independent, Flexible NO 2 and $\mathrm{NH}_{3}$ Gas Sensors Based on $\mathrm{SnS}_{2}$ Hybrid Functional Graphene Ink. ACS Appl. Mater. Interfaces 2020, 12, 997-1004. [CrossRef]

91. Geng, X.; Zhang, C.; Debliquy, M. Cadmium sulfide activated zinc oxide coatings deposited by liquid plasma spray for room temperature nitrogen dioxide detection under visible light illumination. Ceram. Int. 2016, 42, 4845-4852. [CrossRef]

92. Vijjapu, M.T.; Surya, S.G.; Yuvaraja, S.; Zhang, X.; Alshareef, H.N.; Salama, K.N. Fully Integrated Indium Gallium Zinc Oxide $\mathrm{NO}_{2}$ Gas Detector. ACS Sens. 2020, 5, 984-993. [CrossRef]

93. Yu, H.; Yang, T.; Wang, Z.; Li, Z.; Zhao, Q.; Zhang, M. p-N heterostructural sensor with $\mathrm{SnO}-\mathrm{SnO}_{2}$ for fast $\mathrm{NO}_{2}$ sensing response properties at room temperature. Sens. Actuators B Chem. 2018, 258, 517-526. [CrossRef]

94. Qin, Y.; Wang, Z.; Liu, D.; Wang, K. Dendritic composite array of silicon nanowires $/ \mathrm{WO}_{3}$ nanowires for sensitive detection of $\mathrm{NO}_{2}$ at room temperature. Mater. Lett. 2017, 207, 29-32. [CrossRef]

95. Xu, H.; Zhang, J.; Rehman, A.U.; Gong, L.; Kan, K.; Li, L.; Shi, K. Synthesis of NiO@CuO nanocomposite as high-performance gas sensing material for $\mathrm{NO}_{2}$ at room temperature. Appl. Surf. Sci. 2017, 412, 230-237. [CrossRef]

96. Sonker, R.K.; Yadav, B.C. Development of $\mathrm{Fe}_{2} \mathrm{O}_{3}-\mathrm{PANI}$ nanocomposite thin film based sensor for $\mathrm{NO}_{2}$ detection. J. Taiwan Inst. Chem. Eng. 2017, 77, 276-281. [CrossRef]

97. Liu, Z.; Yang, X.; Huo, L.; Tian, X.; Qi, T.; Yang, F.; Wang, X.; Yu, K.; Ma, F.; Sun, J. P-CuPcTS/n-SnO 2 organic-inorganic hybrid film for ppb-level $\mathrm{NO}_{2}$ gas sensing at low operating temperature. Sens. Actuators B Chem. 2017, 248, 324-331. [CrossRef]

98. Su, P.-G.; Zheng, Y.-L. Room-temperature ppb-level $\mathrm{SO}_{2}$ gas sensors based on $\mathrm{RGO} / \mathrm{WO}_{3}$ and $\mathrm{MWCNTs} / \mathrm{WO}_{3}$ nanocomposites. Anal. Methods. 2021, 13, 782-788. [CrossRef]

99. Liu, L.; Liu, S. Oxygen Vacancies as an Efficient Strategy for Promotion of Low Concentration $\mathrm{SO}_{2}$ Gas Sensing: The Case of Au-Modified $\mathrm{SnO}_{2}$. ACS Sustain. Chem. Eng. 2018, 6, 13427-13434. [CrossRef]

100. Chaudhary, V.; Singh, H.; Kaur, A. Effect of charge carrier transport on sulfur dioxide monitoring performance of highly porous polyaniline nanofibres. Polym. Int. 2017, 66, 699-704. [CrossRef]

101. Liu, Y.; Xu, X.; Chen, Y.; Zhang, Y.; Gao, X.; Xu, P.; Li, X.; Fang, J.; Wen, W. An integrated micro-chip with $\mathrm{Ru} / \mathrm{Al}_{2} \mathrm{O}_{3} / \mathrm{ZnO}$ as sensing material for $\mathrm{SO}_{2}$ detection. Sens. Actuators B Chem. 2018, 262, 26-34. [CrossRef]

102. Choeichom, P.; Sirivat, A. Discriminative sensing performances of ZSM-5, Y, mordenite, ferrierite, beta, 3A, 4A, 5A, and 13X zeolites towards sulfur dioxide. Ionics 2018, 24, 2829-2841. [CrossRef]

103. Yadav, A.A.; Lokhande, A.C.; Kim, J.H.; Lokhande, C.D. Improvement in $\mathrm{CO}_{2}$ sensing characteristics using Pd nanoparticles decorated $\mathrm{La}_{2} \mathrm{O}_{3}$ thin films. J. Ind. Eng. Chem. 2017, 49, 76-81. [CrossRef]

104. Panes-Ruiz, L.A.; Shaygan, M.; Fu, Y.; Liu, Y.; Khavrus, V.; Oswald, S.; Gemming, T.; Baraban, L.; Bezugly, V.; Cuniberti, G. Toward Highly Sensitive and Energy Efficient Ammonia Gas Detection with Modified Single-Walled Carbon Nanotubes at Room Temperature. ACS Sens. 2018, 3, 79-86. [CrossRef] [PubMed]

105. Han, B.; Wang, H.; Yang, W.; Wang, J.; Wei, X. Hierarchical Pt-decorated $\mathrm{In}_{2} \mathrm{O}_{3}$ microspheres with highly enhanced isoprene sensing properties. Ceram. Int. 2021, 47, 9477-9485. [CrossRef]

106. Wu, X.; Wang, H.; Wang, J.; Chen, J.; Shi, L.; Han, B.; Tian, X. Hydrothermal synthesis of flower-like $\mathrm{Cr}_{2} \mathrm{O}_{3}$-doped $\mathrm{In}_{2} \mathrm{O}_{3}$ nanorods clusters for ultra-low isoprene detection. Colloids Surf. A Physicochem. Eng. Asp. 2021, 620, 126606. [CrossRef]

107. Wang, P.; Dong, T.; Jia, C.; Yang, P. Ultraselective acetone-gas sensor based ZnO flowers functionalized by Au nanoparticle loading on certain facet. Sens. Actuators B Chem. 2019, 288, 1-11. [CrossRef] 